\title{
A Comparison of Open Ended and Closed Curricula and the Effect of Each on Creativity Cultivation in the Elementary Art Classroom
}

Emily Drennon

Follow this and additional works at: https://researchrepository.wvu.edu/etd

\section{Recommended Citation}

Drennon, Emily, "A Comparison of Open Ended and Closed Curricula and the Effect of Each on Creativity Cultivation in the Elementary Art Classroom" (2017). Graduate Theses, Dissertations, and Problem Reports. 5513.

https://researchrepository.wvu.edu/etd/5513

This Thesis is protected by copyright and/or related rights. It has been brought to you by the The Research Repository @ WVU with permission from the rights-holder(s). You are free to use this Thesis in any way that is permitted by the copyright and related rights legislation that applies to your use. For other uses you must obtain permission from the rights-holder(s) directly, unless additional rights are indicated by a Creative Commons license in the record and/ or on the work itself. This Thesis has been accepted for inclusion in WVU Graduate Theses, Dissertations, and Problem Reports collection by an authorized administrator of The Research Repository @ WVU. For more information, please contact researchrepository@mail.wvu.edu. 
A Comparison of Open Ended and Closed Curricula and the Effect of Each on Creativity Cultivation in the Elementary Art Classroom

\section{Emily Drennon}

Thesis Submitted to the College of Creative Arts at West Virginia University

in partial fulfillment of the requirements for the degree of

Masters of Arts in Art Education

Terese Giobbia, Ph.D., chair Rhonda Reymond, Ph.D. Amy Schissel, M.F.A.

Department of Art Education

\section{Morgantown, West Virginia}

2017

Keywords: creativity, education, elementary, open-ended curriculum Copyright 2017 Emily Drennon 


\section{ABSTRACT \\ A Comparison of Open Ended and Closed Curricula and the Effect of Each on Creativity Cultivation in the Elementary Art Classroom}

\section{Emily Drennon}

This study compares the various curricula in place within art education classrooms in West Virginia. During the pivotal stage of development and height of creativity, children at the elementary level possess great creative abilities and innovative thinking. Thus, this study takes an in-depth look at the effect these curricula have on student creativity. Primarily, what effect does an open-ended curriculum have on the creativity of elementary art students? In this pilot study, both a closed curriculum, and open-ended curriculumbased lesson were exercised on a small group of first and second grade students in order to compare the visual, innovative, and creative differences in the processes and products of each individual curriculum. Using a rubric, a panel of art educators and practicing artists were asked to give their opinions on their perceptions of creativity in the products each of the different lesson plans produced. Panelists were not given any information on the participants or lessons used. They were simply asked which set of images they found to be more creative. The findings appeared to suggest that panelists found the open-ended lesson to produce the most innovative results, and thus supported an open-ended curriculum. 


\section{ACKNOWLEDGMENTS}

I would like to thank Dr. Giobbia for her advice and encouragement, not only throughout the process of the writing of this work, but during the entirety of my pursuit of my Masters of Art Education at West Virginia University. I would also like to thank Dr. Reymond, as well as Professor Schissel for their contributions, advice, and expertise, as well as for their involvement in my thesis committee.

I would also like to thank the wonderful, spirited children I had the opportunity to work with, as well as the talented, informed, and passionate panel of individuals who were willing to give their input and apply their expertise to the products of my students. 


\section{TABLE OF CONTENTS}

\section{LIST OF FIGURES}

Figure 1. House on pink paper

Figure 2. Teal and purple house

Figure 3. Student A showing artistic process.

Figure 4. Student B showing artistic process.

Figure 5. Red, blue and brown house.

Figure 6. Funky Monkey

Figure 7. Artistic process with coffee filters.

Figure 8. Pink and orange rings.

Figure 9. Art using font and type.

Figure 10. Findings pie chart.

\section{CHAPTER 1- Introduction}

1.1 Study Topic

1.2 Significance of Study

1.3 Problem Statement

1.4 Definition of Terms

\section{CHAPTER 2- Literature Review}

2.1 Introduction

2.2 A Brief Overview of the History of Art in Elementary Schools

2.3. Constructivism and Piaget Theory

2.4. Stages of Artistic Development

2.5 The Role of the Art Educator in Contemporary Art Education

2.6 Curriculum Development in the Elementary School Classroom

2.7 Conclusion

\section{CHAPTER 3- Methodology}

3.1 Introduction

3.2 Methods

3.3 Site

3.4 Participants

3.5 Limitations

\section{CHAPTER 4 - DATA COLLECTION}

\section{CHAPTER 5- DATA ANALYSIS}




\section{CHAPTER ONE}

\subsection{Study Topic}

As a multifaceted discipline, art welcomes fluidity and encourages change and growth of the student. Within the art classroom, one should find that the opportunities for self-expression are endless, and that creativity is continuously stimulated through the arts by way of engaging each student's imaginative processes, resulting in a visual response that is individualistic and deeply personal. Students should feel inspired to express themselves through innovative ways of thinking within the art classroom. It is an issue then, in my opinion, when students are exposed to a closed-curriculum model—one in which they are not encouraged to think innovatively and create intuitively. While it is important to provide students with some guidance at the start of each project, an art education that is entirely guided caps creativity. It is crucial that art instructors be passionate about their work, and that they reflect that drive in their students. Artists discover themselves through their art-making process, something that is hindered by a heavily guided curriculum.

This proposal discusses the development of an open-ended curriculum within the art classroom. Through my own personal observations of art teachers in the classroom, analysis of the curriculum used in those classrooms, and an assembled panel of art educators who judged student work, my research investigated whether open-ended curriculum development and implementation within the art classroom cultivates creativity within the elementary classroom and how alternative curricula may affect creative 
development. Through my research, examined the benefits and disadvantages of both openended and closed-curricula in the art classroom. I wanted to understand the effect the different curricula have on the cultivation of creativity in students. I wanted to know if an open-ended curriculum stimulates creativity, growth, and innovation within students. Art educators aim to incorporate the goal of transmitting knowledge of personal creative ability during the process of artistic production. As a future art educator, I want to encourage students to take risks and to create as innovatively as possible. This pilot study demonstrates the curriculum type that allows for the most personal growth. Does this approach to art education benefit students and inspire them to create independently, freely? The research questions, which framed this research, are:

1 Does an open-ended curriculum inspire creativity among students?

2 Does an open-ended curriculum inspire different modes of creation?

3 Does an open-ended curriculum inspire thoughtful innovation?

\subsection{Significance of the Study}

Heavily guided art instruction hinders creative development, and results in each student telling the same visual story, as end student product looks, feels, and acts all the same. Instead of the student creating a personal narrative, they have simply regurgitated what they were instructed to create. This defeats the purpose of artistic expression, but is a common issue in the art classroom, particularly in rural areas, where funding for the arts is limited and it is not viewed as an important discipline to study—often it is cut out of educational settings entirely, or is instructed on a limited basis by an individual not necessarily trained in the arts. These are the issues I have observed within art education, 
primarily in the Appalachian region - that creativity is hindered by closed curriculum and that importance is not placed on the arts at the elementary level. This is an issue especially in elementary education, when learning is at its peak, and students are incredibly creative. Children enjoy creating, and do so innately through art and storytelling, thus they should be urged to do so-yet they are often restricted within the art classroom at an early age, and consequently artistic innovation decreases.

\subsection{Problem Statement}

The standardization of the school environment in general has led to an abundance of students who look to their art teachers for answers on what to create next, instead of reflecting internally for the answer (Slattery, 1995). Students at this age have no lack of creative ability, until they are socially learned to view success as having a singular answer, thus discouraging risk taking. Artistically, students should be encouraged to be entirely authentic, in order for the most thoughtful and inventive artwork to be produced. By simply talking to a child, we as educators and investigators are exposed to active imaginations, their zest for life, and creative innovation. As a future art educator, I want to encourage students to create actively, imaginatively, and independently. Squandering inherent creativity may lead to a more restrictive learning environment and this proposal investigates whether better art can be made through the atmosphere of the art classroom in this stage of child development.

Children should be encouraged to create art based on personal narratives, which is achievable through open-ended curriculum and passionate instruction. It is sad that art is often overlooked and undervalued within any given school curriculum. Obviously, this truth varies from region to region; some embrace the arts fully and emphasize their 
importance. There is a great need for art education, particularly at this stage in development; however, we often see art education programs being cut, minimized, or forgotten. In certain parts of West Virginia, in particular, there are entire regions that do not even have an elementary art education program established. At one of the heights of creativity (childhood), the arts, be they visual, verbal, kinesthetic, etc. are being ripped mercilessly from those individuals who respond to it the most. During a time where students think and make in a highly creative manner, an effective art education program is owed to them. More importantly, they are owed an art education that allows them to explore their worlds and themselves. Pablo Picasso once stated that it took him an entire lifetime to paint like a child (Picasso, year unknown). I think it is important that children simply never "unlearn" this ability and that they always paint like children. Children are given the incredible gift of creative thought and execution. Art education should aim to hone this gift. It is all too simple to give students the answer to a creative problem. We must have them cultivate this answer within themselves.

\subsection{Definition of Terms}

Closed-curriculum: closed curriculum models are strictly sequenced (Freedman, 2003).

Closed Objective (Freedman, 2003)

- Describes what the student will know or be able to do as a result of the lesson

- Indicates what the student will do to demonstrate they have learned

- Demonstrates how well they will complete the artwork, given a specific standard

- Under what conditions?

Constructivism: theory of knowledge that argues that humans generate knowledge and meaning from an interaction between their experiences and their ideas. It is a philosophical theory on the nature of "knowing," widely considered to be one of Jean Piaget's major findings (Peterson, 2012).

Enacted curriculum: Enacted curriculum refers to instruction and what happens within the classroom (Freedman, 2003). 
Hidden curriculum: Hidden curriculum refers to the things students learn in school that are not necessarily planned by the educator or incorporated into the overt, planned, enacted curriculum. Hidden curriculum may result in both positive (i.e. teacher as caretaker) and negative thinking (i.e. stereotypes) (Jackson, 1968).

Interactive curriculum: Interactive curriculum responds to the students' experience outside of the classroom. The input of each student is welcomed in this curriculum, and often extends beyond what is learned from within the classroom. Interactive curriculum often responds to issues raised by the hidden curriculum. Interactive curriculum responds to change as it occurs and embraces modern visual and social culture (Freedman, 2003).

Interdisciplinary curriculum: Art curriculum should integrate traditionally different subject matter, as art is inherently multidisciplinary. This curriculum challenges what, when, and where art should be integrated into multidisciplinary education (Freedman, 2003).

Null curriculum: Students learn from what is not taught. This is particularly important within the artistic context as students continuously learn from visual culture, and they construct their worlds visually (Freedman, 2003).

Open-ended curriculum: refers to experiences that are carefully planned but with characteristics that invite students to take the lead in exploring ideas, solving meaningful problems and develop their creativity. Teachers plan rich and interesting activities; provide unique materials, environments, and projects that have many possible outcomes for student learning. Openended curriculum afford the learner greater choice in determining the content and progression of their curriculum.

Open Objective (Freedman, 2003):

- Infuses concepts and skills.

- Connects emotions to ideas.

- Involves problem-finding and/or problem solving.

- Each student is expected to produce a different response to the lesson.

Planned curriculum: made up of a conceptual framework, rationale, and structure of curriculum. Resources, lessons, and visual aids to be used are also included. In other words, the planned curriculum refers to the creation of a curriculum (Freedman, 2003).

Spiral-curriculum: a course of study in which students will see the same topics throughout their school career, with each encounter increasing in complexity and reinforcing previous learning. Spiral curriculum intends to increase knowledge as well as reinforce it (Freedman, 2003). 


\section{CHAPTER 2}

\subsection{Review of Literature}

“An artist manipulates, combines, and edits images or forms in the process of making an individual work, ideas and methods make themselves apparent as the work is realized," (Walker, 2011, p. 12). In the process of making art, the students discover themselves, make mistakes, and ultimately create innovatively. The following works of literature emphasize the importance of allowing individual students to explore themselves and their ideas artistically. Many of these works, unsurprisingly, lend themselves to an open-ended curriculum. While it is clear that the role of the art educator is to instruct and conceptualize for students the elements of art and principles of design, it is also important hat the art educator not guide students so much so that they lose the ability to innovate of their own accord.

\subsection{Brief History of Art Education in American Elementary School Classrooms}

Two centuries ago, art education was something that was unheard of. However, Benjamin Franklin advocated for an art education in 1749. Franklin's efforts were met with much opposition and many reverses. In Franklin's Proposed Hints for an Academy, he strongly advocated for an art-based education, where art was a primary characteristic of the pedagogy he had proposed. While these changes were met with opposition in 1870 , provisions for an art education were set into motion, and art education has been embraced to some degree in the American school system ever since (University of North Texas). Over time, belief in an art-based education has waxed and waned. For the purposes of this 
study, I have chosen to focus in- on art education within the West Virginian elementary classroom. My desire to focus on this region stems from both my close association with the state, as well as a viewpoint on art education that I often do not agree with. Art education programs are often cut and minimized, due to lack of funds or lack of value of the arts. In fact, in Wood County, an elementary art education program is not even in place. In areas like this, you can see creativity fall to the wayside, and the standardization of creative thought begin to take place.

\subsection{Constructivism and Piaget Theory}

When considering Piagetian theory on cognitive development and its relationship with open-ended curricula, psychologist Jean Piaget investigated the nature of knowledge itself, and "how humans come to amass knowledge, reconstruct it, and implement it in their daily lives" (Peterson, 2012, p.884). Piagetian theory was largely influential within the field of developmental psychology, and was an explanation for human construction of knowledge from very early developmental stages of life. Piaget believed that children acquired knowledge from the world around them, and used this acquired knowledge to make sense of their worlds. When discrepancies occur between what children already know and the world around them — their environment — children analyze these discrepancies and adjust their understanding accordingly. Essentially, human beings continuously learn from the world around them, and make sense of their worlds through reconstruction of knowledge and ideas; through reorganization of their thoughts, understanding, and analysis of what is and what is not (Peterson, 2012). Piagetian theory directly relates to open-ended curriculum, and thus has greatly influenced learning development through this curriculum (Peterson, 2012). In order to learn from art in the most depth, students must be allowed to 
explore their worlds and make sense of them in a way that is uniquely their own. Openended curriculum allows for this-for self-exploration, for the gathering of knowledge from the world, for varied, beautiful artistic journeys and outcomes.

As observed within the Piagetian theory of cognitive development, reorganization and making sense of our worlds occurs at a very early age, and continuously develops and becomes more refined through the developmental stages of life. Piagetian theory has often been considered and applied to stages of artistic development. Time and time again, researchers tend to agree that children seem to show similarities within the visual representations of their worlds at specific stages of development. At the earliest stage of development, representing the ages between eighteen months and three years of age, children tend to represent their world through scribbling, without paying much attention to specific detail or accurate representation. From three to seven years of age, children then enter what is known as the symbolic stage, where objects begin to be fundamentally recognizable. The final stage of development accounted for within the artistic realm is from ages seven years and onward, which is known as the realism stage, where a clear attention to detail and differentiated form is made (Peterson, 2012). Open-ended curricula in the art classroom allows for students to explore the stages of artistic development in a way that spurs creativity. As students begin to enter the realism stage, student work can begin to lack differentiation and visual interest; they begin to interpret the world literally and create art that is not personal, if they are not encouraged to continue to create from an inward, interpretive place. This research delves into the thought that, if beginning in the symbolic stage of artistic development, students were encouraged to create from their imagination, and from ideas of their own accord, they would continue to be more so creative as they 
move into the realism stage. I feel that many more students would be artistically successful if they were not made to think that their work has to look like exactly what is in front of them, or how they assume a given object should look.

\subsection{Lowenfield's Stages of Artistic Development}

The scribbling stage is interesting when taking into consideration the complexity of development and the human psyche, and the early recognition that there is a world to interact with; to visually represent. From an early age, children represent their worlds very abstractly, with fluidity, and through a lens that captures the world uniquely, in a way that is often only perceived and accessible at this stage of development. While perception of the world changes with development, art education, at least one that cares about the creative innovation and growth of the student, aims to cling to the imaginativeness of childhood. It is important to be cognizant of the abstract patterns of thought found in the early stages of development, and to allow them to carry throughout all stages of artistic development and to be integrated into the classroom. Lowenfield's studies on development indicate the artistic changes each individual student will go through—abstract thought leads to more innovative artwork, so it is important to activate these areas of thinking through art education.

Austrian art educator, Viktor Lowenfield, described the harm that is caused by overly restrictive schooling and parenting, in which children do not develop the capacity for sensing and expressing their own thoughts and perceptions. Lowenfield experienced firsthand the devastating effect of rigid dogmatism and disrespect for individual differences, stating "I know that force does not solve problems and that basis for human relationships is usually created in the homes and kindergartens" (Gude, 2009, p.9). Thus, 
Lowenfield argued for a free and individualistic art education, acknowledging the fact that artistic expression is best honed in the least restrictive environment. Lowenfield believed that harsh discipline and lack of opportunities for creative expression created individuals who would be susceptible to totalitarian control. I do not feel that Lowenfield was far off in these assumptions, as earlier stated, I feel that the arts have been threatened by a totalitarian educational mindset. While many art educators approach their classrooms with the goal of innovative artistic creation, the overall standardized mindset towards academics has undoubtedly hindered and curbed the creativity of elementary age students within the art classroom.

\subsection{The Role of the Art Educator in a Contemporary Art Curriculum}

Olivia Gude emphasized the importance of early and recurring experience of art education rooted in individual self-awareness and free exploration (Gude, 2009). An everpresent problem within art education, particularly during the elementary school years of academic and artistic development, is that students are often encouraged to create in an expected, stable, and norm-embracing manner. During a highly creative time of development, it is artistically defeating and limiting to have specific visual expectations laid out for young artists. That is, for an absolute expected product to result from an artistic process hinders the creative process, often long-term. As students continue their art education, they often unremittingly seek to be given answers, so to speak, to their creative dilemmas. Instead of working through the conceptual barriers students may face, they desire the creative solution to be given to them, often by their instructor. The standardized vantage point of education has had negative effects on individual creativity and students have grown used to achieving academic conclusions that have a single correct answer- 
something that is not intrinsic to the world of art, and is in fact, quite opposite. Visual art is a discipline that lends itself to multiple correct answers as well as a discipline that allows for a relatively large parameter of subjectivity.

Gude also acknowledges that a child gains a sense of him/herself by freely playing with materials, images, and ideas (Gude, 2009). She makes the hopeful claim that, in art making, there is an importance in the deeply felt connection between self, process, and product. Hence, a good art education encourages the student to relate their art making to their inherent self; to create expressively. When we allow students to explore their individual identities and art-making processes within the art classroom, we allow for the students to learn about themselves, their peers, and their surrounding visual culture. When students are able to feel deeply emotional and physical during the creation of a work, the inner experience of the student and the experienced outer world are able to come into the same plane; this heightened dual awareness is a defining characteristic of the artistic process - artists should be able to create freely and openly in order to heed the most creative results (Gude, 2009).

Art educators, according to Gude, have the responsibility to hone a democratic society through individual effort. A democratic society begins with individuals who perceive fully, and consciously integrate perceptions into complex constructions, and habitually act on the basis of our deepest awareness. An inherently self-aware student, will thus create effectively, as well as contribute positively to a democratic society. A democratic society, within the art classroom, is one that lends itself to visual thoughtfulness and identity awareness in art making. Through experimentation with media and aesthetic and theoretical methodologies, students represent their life experiences - in images, words, 
sounds, movements - through contrasts and comparisons, juxtapositions, and layering, reverberations, and silences. Through making and remaking the story, and the images, the student makes the self. The artistically aware person recognizes deeply felt aspects of experience that are irreducibly ambiguous, beyond words, and beyond representation (Gude, 2009). An artist that is in tune with their creative call will refer to their inner world for creative insight - they will not seek the answers to be given to them externally. An open objective art classroom lends itself to innovative and individual creative thought.

Gude states that quality art education creates individuals who have the propensities and skills to form communities of discourse, as well as spaces of shared and contested meaning. Despite difficulties, misunderstandings, seemingly irreconcilable disagreements, and all manners of setbacks, to be a truly democratic society — we must persist in our individual and collective investigations of possibility, we must remain committed to thoughtfully engaging each other in our endeavors to make meaning and to make meaningful life together (Gude, 2009). Gude's philosophies on art education, and on democratic ideals, are applicable to both the creative process, as well as to life itself. The art-making process allows for self-discovery, mistakes, learning, and a myriad of outcomes. In good art education, the process and product is an entirely individualistic journey, and will result in a multitude of creations. According to Gude, through making and experiencing art, people generate, apprehend, and hold multiple ways of knowing and being in the world. Quality arts education attunes us to how methods of making are always strategies for being, and the curriculum of quality art education is centered on learning about and utilizing strategies to produces individual and cultural meaning, and a meaningful visual and social culture. Thus, individual discovery and insight are intrinsic to 
the quality art education. Gude argues that people who have participated in quality arts education identify the importance of free expression for themselves, and for others (Gude, 2009). In an art classroom that hinges on the concepts of self-development and inner artistic thought, students will garner more respect and creative innovation in their own learning, as well as in the analysis in the work of others.

In Gude's article Playing, Creativity, and Possibility, she focuses on the issue that, while virtually all art educators list "enhancing creativity," as a desired outcome of their programs, analysis of lesson plans used in schools suggests that in practice, very little curriculum is specifically geared to developing creative abilities (Gude, 2010). As art educators, we need to focus on encouraging creativity throughout the process and production of our students, and must implement these concepts within the development of our classroom. It is clear academic reform in the art classroom is necessary. In a world where students are encouraged to seek a "right" answer, it is our job to allow them to see the beauty of open-ended creation, a realm where there are multiple right answers, and a discipline that allows for the seeking and discovery of the self. Core objectives for quality creative curriculum, such as stimulating free ideation, encouraging experimental approaches to making, and supporting students in identifying and manifesting deeply felt idiosyncratic experiences (Gude, 2010).

In Playing, Creativity, and Possibility, Gude states, "I realized I strongly identified with the experience of the overworked, discouraged teacher, and not with the internal experience of the student. The student is not lazy or spiritless, but the student is spirited, without the spirit of fearless exploration needed to make art," (Gude, 2010, p.32). As teachers, it is important that we seek to know our students and to understand their creative 
processes and products. An artist must make a commitment to actively and seriously engage the materials and forms at hand while simultaneously remaining loose and experimental. According to Gude, teachers can readily list many conditions that inhibit the development of creativity in their students - self-consciousness in front of peers, overscheduling that does not leave time for creative daydreaming, hours immersed in passively watching T.V., or actively playing video games, schools that focus on getting the one right answer, and a society that judges successes on standardized test scores and the size of bank accounts (Gude, 2010). In an academic realm driven by standardized thought and measures of success, it is important to "un-teach" these thought modalities to students.

Standardization and expected outcome depletes creativity and hinders visual interest in student product. It is important for art educators to embrace a freely creative and independent atmosphere within their studio class, in order to be conducive to creativity.

Art standards, according to Gude, do not represent the deep experiences of immersion, wonder, and not knowing that are described by creative individuals (Gude, 2010). While is it crucial to teach art lessons with artistic standards and objectives in mind, it is also important for art educators to emphasize the importance of the individuality of artistic process, to make known both the inner and outer world working in congruence for the most successful and sound visual outcomes; the art educator needs to let it be known that it is okay to take an individual approach to a project, that mistakes and inquiries during the creative process are a positive thing, and that there are simply parts of the creative process that cannot be standardized, nor completed in a standardized manner.

Gude stresses that art educators create a climate in which the individual's experience is valued and understood, a climate in which the individual is not judged for 
how well he or she meets a predetermined model of process or product. Gude states that these activities can be thought of as remedial education for all whose creative capacities have been damaged by too much time in dehumanizing and overly regimented educational systems (Gude 2010). Clearly, there is a need, as well as a time and place, for organized thought and regimen. However, too much of a restrictive influence in the art classroom, as previously discussed, completely hinders creative expression and innovation. In art classrooms where regimen is heavily enforced, often there is not much variety to be found in the artwork, conceptually or visually. For example, students exposed to abstract thought processes, such as identifying images within randomized ink markings, students cultivate an ability to consciously alter ones perception in order to access other ways of seeing and knowing. Abstract, open-ended lesson design allows a creative maker to foster awareness of the intertwining of the outer world and the inner consciousness. Overall, the primary objective of a creativity curriculum ought to be developing the capacity of students to instinctively respond to situations with playful creative behaviors. When afforded the opportunity, students are able create incredible imagery that shatters traditions and makes way for creative innovation. Carl Rogers, an American psychologist, describes this ability as an "internal locus of evaluation." That is, the strength to trust one's own process and perceptions, however different they may be from socially accepted norms. Astounding artwork is born of risk-taking and the rejection of social, cultural, and visual norms.

Today's students are over-constricted by an education that all too often focuses on knowing a single correct answer, as previously discussed. These same students need guidance in reclaiming their capacities for conceptual, imaginative play. Making should be at the heart of elementary art education, and we should encourage our students, as art 
educators, to explore their own unique thoughts and approaches to creative endeavors, and we should encourage them to be beautifully expressive. According to Gude, students are often not given sufficient opportunities to make artworks that are not tightly controlled by realist or formalist parameters (Gude, 2007). Thus, many students do not believe an artwork to be successful if it does not fit within the expectations of a realist or formalist work. However, as art educators, we know that this is simply not the case. That abstracted, expressionistic, imperfect works also play an important role in the creative process. Because of this expectation cultivated by a standardized academic environment, students will often not perceive a successful work as successful, if it does not mirror what they see in reality, or look like the example they are presented with in class. As students are introduced to embracing a more fluid and intuitive approach to art making, students will begin to access the creative unconscious. Students, who are able to access this part of their own creative mental pathway, will rarely be faced with the common art classroom dilemma of not knowing what to create. Students who are aware of their creative unconscious will create a myriad of artworks. Artworks attract multiple interpretations, and it is not the goal of interpretation to arrive at a single, grand, unified, and composite interpretation.

In Principles of Possibility, Gude states that those students enrolled in an effective art education will generate personal and shared meaning in their art making (Gude, 2007). By its nature, art is an open concept that is always evolving and changing, therefore art students should be ever evolving and changing, and they should be encouraged to partake in complex and creative thought. While there are important elements and principles of art and design that students should be made aware of during their art education, Gude raises the question, "Do we really want students to say that art is 'about' line, shape, color, 
contrast, or repetition" (Gude, 2007, p.9)? On a personal, spiritual, emotional, and physical level, art is much more than the elements and principles it is composed of. It is about the creator themselves, and the world that they exist in. Learning, in the art classroom, begins with creative, deeply personal, primary process play (Gude, 2007).

In Philip Jackson's Life in Classrooms, Jackson argues for the hidden curriculum, and school as a transmitter of ideologies (Jackson, 1968). In the upcoming discussion of curriculum, concepts such as the hidden curriculum, as well as other varying types of curriculum, will be discussed. Jackson discusses those concepts that are learned in the classroom through alternative opportunities or from unplanned occurrences, and that the unplanned curriculum in school, as well as the intentioned curriculum, act as vehicles for thought processes that extend well past the walls of any given school. It is my argument that open-ended curriculum drives creativity and produces the most successful visual outcomes. However, the many facets of curriculum work together to form the complex and adaptable environment that is the art education classroom.

According to art educator Kerry Freedman, open-ended curriculum can be defined as having something to do with students creatively demonstrating ways in which they have uniquely constructed knowledge (Freedman, 2003, p.15). Once again, this hearkens back to the vision of Piagetian theory, and reinforces the concept of constructing one's world through acquired knowledge. Open-ended objectives relate to and connect emotion and individual ideas to art making, and thus, employs art to be deeply personal and explorative. When art is individualistic, it is a creative visage of each student's world. Allowing for uniqueness and distinctiveness in art making propels creativity and ingenuity.

Freedman addresses that curriculum is a creative process in and of itself, and comes 
to recognize that it is crucial to what and how your students learn. As a result, states

Freedman, curriculum should be as transparent as possible. This means that students should be told why they are leaning the things we hope they will learn and how these things will improve their lives. They should be made aware of the importance of artistic expression in human existence, the role it has played in recording history, the connections between art and other subject areas, and the influences of the visual arts in students' everyday lives (Freedman, 2003).

It is important to address the variant curricula that can be found within the art classroom, as suggested by Freedman. Curriculum development involves both the planned and enacted curriculum. Essentially, students learn from both what is planned by the instructor, and from things that occur spontaneously within the art classroom, which can take the form of an artistic discussion, interpretation of visual imagery, or their own artistic production. Students can also learn from what is not taught, which is known as the null curriculum (Freedman, 2003). As stated earlier, many rural Appalachian schools do not place importance on the arts, thus students learn that art is not significant, and their interest in it will dissipate within the educational realm. I agree with Freedman that this is untrue, however, as visual culture shapes life itself and gives structure to our worlds; art should be incorporated at the elementary level, as students are so visually aware and intrigued by imagery at this stage. Another aspect of curriculum is the hidden curriculum - these are things that students learn, over time, which the instructor did not necessarily intend, yet convey through their instruction.

\subsection{Curriculum Development}

During curriculum development, it is important that objectives are developmentally 
relevant, so process and production goals can be achieved. Thus, at the elementary level, it is crucial to keep the cohort age group in mind, and to design a curriculum that will lead to their artistic success. Objectives are specific expectations given to students so they know what they are intended to create.

A planned curriculum is made up of a conceptual framework, a rationale, an explanation of the structure of the curriculum, a content scope and sequence, units and lessons, and supporting resources, such as visual imagery (Freedman, 2003). It is this process that, we as educators, cognize what it is we want our students to take away from the lesson - a realization of idealism, and what it is we want to convey through artistic process. During the construction of the conceptual framework of a lesson, it is key to keep social ideals in mind in order for students to relay their artistic production to their own individual lives. The way content is presented to students will determine whether or not they will pursue and integrate art in the future, so it is fundamental to present artistic information in a way that students can relate it to their identity, and be passionate about it. I reiterate that open-ended objectives makes this possible, as through these kinds of projects, students are urged to create their own path and individual product—one that is expressive and explorative.

The curriculum rationale provides depth and gives meaning to the creation of a specific product, and explains how and why it is significant to a student's development and educational growth (Freedman, 2003). The rationale justifies the inclusion of visual culture in school, and what it is we, as educators, want our students to obtain from a particular lesson. The beautiful thing about art is that it is deeply personal, and students can derive a myriad of lessons learned from it. Through art, students learn about themselves, their visual 
culture, their peers, and form opinions social matters.

During curriculum design, several organizational structures of curriculum should be taken into consideration. Each organizational structure should be considered and approached, as each lends its own strengths and weaknesses. These organizational structures include; spiral curriculum, interactive curriculum, event experiences, and interdisciplinary curriculum (Freedman, 2003). I will discuss each in further detail.

Spiral curriculum builds upon previous knowledge, and gradually increases both skill and content knowledge in students, as it not only introduces new concepts with each lesson, but also revisits foregoing concepts and structures (Freedman, 2003). I feel that spiral curriculum is necessary within the art classroom, as it allows for visual cohesiveness and deeper understanding of artistic concepts, as the concepts are built upon. Thus, spiral curriculum is superior to a linear curriculum, where concepts are not revisited and new ideas are simply added with each new lesson. A spiral curriculum allows for students to make interdisciplinary, individual, social, and historical connections within the art classroom.

Interactive curriculum relates to the student's life outside of school and is essentially the rapport developed within the art classroom, enacting elements of the hidden curriculum. This is a kind of negotiated curriculum, where students play as critical of a role as the instructor. The students are responsible for much of the content learned during an interactive curriculum, thus this allows for a learning culture that is both visual and one that extends beyond the art classroom (Freedman, 2003). Which is what we, as educators, should desire - curriculum should surpass the mere walls of the classroom and help build and develop the lives of students outside of the educational realm? When a discipline 
relates to the very life of an individual student, this enriches art content within the classroom - the student transfers what they have learned within the art classroom and integrates it into their life experience. As through art, and life, we learn.

Event experiences are incredibly memorable events in which both the student and teacher can engage in an artistic experience that is separate from the typical art classroom practice, such as a museum visit or artistic performance (Freedman, 2003). Integrating these kinds of experiences into the art classroom is critical, as it lends a new element to the learning experience and students often remember these events fondly, as they are able to actively engage with a work of art or performance itself. These kinds of experiences may inspire a student to develop specific artistic interests and practices, and allow them to see the world of art with a new lens and propel growth in the student. I feel these experiences are meaningful, especially at the elementary level, as these experiences will stand out in the students' mind and perhaps shape their artistic involvement in the future.

Interdisciplinary curriculum integrates art with varying disciplines. Art is inherently interdisciplinary, as it relates to history, culture, etc., thus it lends itself to being an interdisciplinary curriculum. Freedman states that, in the past, this has been seen as a threat to art education, as it allows for art to be fully absorbed into other curriculum (Freedman, 2003). This is a very real issue in certain rural areas in Appalachia, even today—some counties in West Virginia do not incorporate art into their curriculum at the elementary level, but rather have it sparingly taught throughout the academic year. However, integration without elimination is possible, and it is appropriate to teach art interdisciplinary, so long as the instructors can provide equal amounts of attention to each discipline. 
Visual culture is incredibly complex,- - it incorporates the individual, their community and culture, social ideals and issues. Thus, it is critical to break it down into art units and lessons, especially at the elementary level, so that it can be more easily understood and adapted and integrated into students' everyday life experiences. Two kinds of objectives are necessary when teaching visual culture-closed and open objectives (Freedman, 2003).

Open objectives, as discussed earlier, result in a myriad of responses in each student to a lesson, which I believe to be critical to the art experience and unique artistic production. This will be discussed throughout my research. Closed objectives are used in all school subjects, thus I will not deny their significance in academic growth. However, closed objectives simply state what the student will learn or be able to do as a result of a lesson. While this is necessary in art, to have fundamental understanding and lessons centered on these fundamentals of artistic learning, I do not feel closed objectives necessarily inspire creative growth, rather they further develop a technical skill. At the elementary level, as discussed in Piagetian theory, I believe it to be more enriching to focus on imagination and innovation in art, than it is to develop a technical skill. These things can be taught as students mature. Creativity is not something to be squandered, and children are highly artistic beings. It would simply be a disservice to them to inhibit their artistic ingenuity and innovation. Open objectives should be used at the elementary level in order to inspire artistic growth and unique, personal narratives. Art should tell a story, not simply relay facts.

Assessments must relate to objectives in art lesson planning, however they should be left open-ended enough to allow for distinctive student production. Freedman states that, 
"this is one great strength of the visual arts; it involves many "correct" answers to a single problem and students can learn valuable lessons from educators' valuing diverse thinking," and I feel this a powerful component of the arts (Freedman, 2003). Lesson planning in the arts should cultivate a multitude of successful solutions to a single artistic question.

Rethinking art education can produce changes that trigger controversy, resistance, and anxiety (Walker, 2015). However, some rethinking is crucial to the successful continuation of art education. Undoubtedly, art educators do not approach their classroom with the intention of a lack of innovation within their students in the art classroom, but it is happening. Due to the comfort students take in familiarity and repetition, art making, is at times, not creative, innovative, or inspiring. It is up to the art educator to establish an art classroom that encourages the students to explore their art making on a deeply personal level, and emphasize the importance of embracing complexity and inventive thought. According to the important art education literary work, The Arts and the Creation of the Mind, by Elliot Eisner, Eisner, "wants to dispel the idea that the arts are somehow intellectually undemanding, emotive rather than reflective operations done with the hand somehow unattached from the head. I argue that many of the most complex and subtle forms of thinking take place when students have an opportunity either to work meaningfully on the creation of images - whether visual, choreographic, musical, literary, or poetic - or to scrutinize them appreciatively. To be able to create a form of experience that can be regarded, as aesthetic requires a mind that animates our imaginative capacities and that promotes our ability to undergo emotionally pervaded experience. Perception is, in the end, a cognitive event. What we see is not simply a function of what we take from the world, but what we make of it," (Eisner, 2002, p.12). When given the opportunity, students 
can create endlessly uniquely, mindfully, and meaningfully. Art is not a discipline devoid of thought; rather it is entirely made up of it.

According to Eisner, "familiarity and routine may provide security, but not much in the way of delight. Surprise is one of the rewards of work in the arts. In addition, it is from surprise that we will most likely learn something. Eisner states that, "art education, focused on the visual world within this frame of reference, is interested in helping students become astute readers of visual images and sensitive, politically informed interpreters of their meanings. The interpretation of meaning, in this view, is in large measure a matter of social and political analysis," (Eisner, 2002, p. 30). Under Eisner's approach to art education, students should be exposed to symbolic and meaningful aspects of interpreting art. In terms of elementary art making, it is important to ask the children what they are creating and why. Children and their art develop largely from the inside out rather from the outside in. Students, instead of working from outside stimuli, often create from their inner dialogue. Eisner states, "not only do artists feed the consciousness of others; the work artists engage in feeds their own consciousness" thus, art is meaningful to both the artist, and the viewer. Coping with materials, making judgments about formal relationships, appraising the features of various qualities in the work are activities that can powerfully heighten our awareness not only of the work acted upon, but of qualities related to those upon which we work."

Art making is a fully aware process. By allowing students to examine materials, tools, and expression, we lead them to more innovative art making. Eisner also makes the proclamation that, "materials matter because they influence what children can think about and how they are likely to engage the work," (Eisner, 2002, p.117). When given unique and 
varying materials, students are more likely to be inventive and explorative in their art making process and production.

In Eisner's literary work, it is stated that, "another lesson that the arts can teach education is the importance of imagination and, as intimated earlier, of refining and using the sensibilities. In the arts, imagination is given license to fly. It poses its factual face. Little time and attention are given to matters of imagination. Yet inventive scholarship depends upon imagination, not to mention the delights that imaginative processes make possible. In schools, we tend to emphasize facticity, correctness, linearity, and concreteness. We tend to underestimate and underplay those imaginative processes that are so characteristic of the cognitive life of preschool and even primary school children. We often fail to nurture a human capacity that is absolutely central to our cultural development (Eisner, 2002, p.198).” In art education, students should be able to create freely and independently, as this is what art naturally lends it to do. In our society and academic approaches, we tend to focus on correctness and measurability. The discipline of art lends itself to imaginativeness, difference, and multiple correct answers. The beauty of the artistic discipline is that it allows for exploration and self-discovery, facets of the elementary-aged students' worldview. It is incredibly important then, to abandon hopes for specific artistic achievements and inventions, and to embrace the multitude of solutions to a given product.

The art making process can be understood as an event of movement through relationships between all things and people as they come into contact. Thus, students can and should integrate all aspects of their life into their art making. Art making is a deeply personal experience, and much of what is experienced within the inner world can be 
communicated through art making. Much art educational practice rightfully values process, as it is associated with skill and intellectual development that occurs over the course of a student's artistic training. The artistic process is often more important than the artistic product. During the process, the students thoughtfully consider their artistic aim, and may come to a variety of decisions about their product, during the artistic process. Time is not something that continues in the background as one produces artwork; it is something that is produced through art making. Art has the power to capture individual moments in time, a side effect of encouraging students to create individualistically and openly. Art acts as a means to communicate moments in the individual's life and how they relate to other beings in their world. Progress happens through process, as intellectual, emotional, and tangible experiences are all components of the process. Art making is inherently a growing process and means of self-exploration. Experience is based in the subjective account of the individual, thus artwork is deeply personal and unique to the individual, often being celebratory of the individual through his or her own style or choice of subject matter. Art, when propelled through an open-ended avenue, allows for creative developments and ingenuity. New, process events lead to growth and new findings during art making in the art classroom. Although there can be repetitiveness and sameness in experience there will also be a host of differences that alter the experience. As children create artwork, they continuously face new changes to their environment and to their own art-making process, which allows for inventiveness in their work. Conceptualization and new discoveries and experiences can change art making - much like in life, art is a learning process and is often reflective of a person's unique journey. Process events allow for new and interesting ideas in children's' artwork (time, place, artist, new knowledge all effect what may or may not be 
created). The process event allows sensation, affect, virtual difference, and time as "nonthinking," but ever-present aspects of art making, to assume significance (Walker, 2004).

In Herbert Read's Education Through Art, Read makes the solid argument that art should be the basis of all education. Through art, students are able to explore their inner world, through propelling complex thought through a means of creation. Read states that, "man should be educated to become what he is; the other, that he should be educated to become what he is not," (Read, 1958, p.139) open-ended work allows for the process of self-discovery, which is what Read is advocating for in his literary work. Through the process of an open-ended art curriculum, students are able to explore themselves, their media, and make decisions that apply to what works for them visually, emotionally, and symbolically. Through the process of creating art, students are able to discover who they are, and who they are not. Through an open curriculum, students are able to explore who they are as creators, as artists, and also the world around them. In self-discovery, one usually comes across many complexities and innovations. Great artwork is created in times of self-exploration, complex thought, and of deeply personal symbolism. Thus, Read discusses that great works of art are both various and complex in their appeal, meaning that, when students are able to create openly, personally, and fluidly, the result is more intriguing, varying artwork (1958).

In his article, Curriculum Development in the Post-Modern Era, Slattery discusses the importance of tailoring curriculum to the ever-changing academic environment (Slattery, 1995). Slattery discusses the concept of "liquid modernity," as the idea of possessing a more fluid understanding. Slattery expresses thoughts about conception and 
planetary existence, and that education has the obligation to stay on par with a rapidly changing social and visual culture. The post-modern paradigm shift lends itself to diversity and rapid change, and exploration of culture. Education should aim to avoid emotional fatigue and educational despair. Slattery believes that the standardization of education is an academic nightmare (Slattery, 1995). Art should never be standardized, as not allowing for artistic expression inhibits creativity. When education allows for personal freedom and creativity, intelligent, complex, more inventive students are cultivated.

In Understanding the Art Making Process, Walker describes how artists pursue meaning, and what it means to be an effective artist. Walker explains that the study of individual artists can be extremely profitable in revealing a range of strategies and methods with the varying elements and principles of art and design (Walker, 2004). Exploring the art making of others can lead to personal artistic development and inspiration for creating new work. It also unveils how each unique artist creates. A study by the Chicago Art Institute recognized that the students, who were judged to be more creative, tended not to utilize pre-conceived ideas or principles, but rather let the art-making solution gradually emerge during the artistic process. Many students prefer to seek balance and stability. For students to seek this familiarity is it a failure to conceive of art making as a discovery process? Walker believes this to be so, as do I. Students who fixate on an expected product, do not often create innovative, interesting work. Student reflection, risk taking, rejecting the conventional and familiar, and exhibiting tolerance of ambiguity enhances creativity and generates more deeply individual work.

In Howard Gardner's, The Disciplined Mind, Gardner explores the concept of multiple intelligences. Open-ended education lends itself to multiple intelligences, as it 
allows for exploration of a variety of cultures, personal truths, and cross-disciplinary discoveries (Gardner, 2000). Gardner states, "the tremendous differences among individuals can actually serve as an ally in the conveying of gritty, intellectual content," (Gardner, 2000, p.150). When students are encouraged to display their individual differences through their art making, a grounds for complex, individual discussion and symbolism is set. The differences that can be found between students and their art making will hone a better understanding of creative thought within the art education classroom. Education is multifaceted in nature; therefore it makes sense to implement an open-ended art education, to allow for students to generate multifaceted productions. Through an openended art education, a successful art classroom and student will produce as many varying artworks as there are individuals.

\subsection{Chapter 3}

\subsection{Methodology}

For the purposes of this study, elementary age students were given two separate lesson plans on different days. One lesson plan was formulated around the closed art curriculum, and the other lesson plan was tailored to the open-ended curriculum format. The students were given each lesson plan without any prompting from the instructor, other than with the expectation to complete the assignment at hand.

The closed lesson plan prompted the students to create a drawing of their dream house. The students were given paper, markers, and teacher-led instruction and demonstration. That lesson plan can be found in the following pages.

3.1 The site of instruction was Mason Dixon Elementary School 
3.2. The participants in the study were seven, first and second grade students

One Day/One Lesson Plan

DAILY PLAN

Name: Emily Drennon

Lesson Title: Draw Your Dream House!

Grade Level: $2^{\text {nd }}$

Skills: Students will gain an understanding of drawing and color usage through the implementation of colored markers. Students will also gain an appreciation of architecture by studying different kinds of houses prior to drawing their "dream house." Additionally, students will engage their inner thoughts by considering what would characterize their dream house.

Social Studies Standards People, Places, and Environments

WV Visual Arts CSO: VA.O.2.5.02-Students will examine and discuss art that reflects personal experiences.

National Visual Arts Standards: Creating-

*Anchor Standard \#1. Generate and conceptualize artistic ideas and work.

*Anchor Standard \#2. Organize and develop artistic ideas and work.

*Anchor Standard \#3. Refine and complete artistic work.

Overall Lesson Objective:

- Students will gain an understanding of their own visual environment, as well as analyze the different types of architecture in the world around them. From that information, each student will draw their dream house to implement their understanding of architecture, refine their drawing skills, and improve their usage of color.

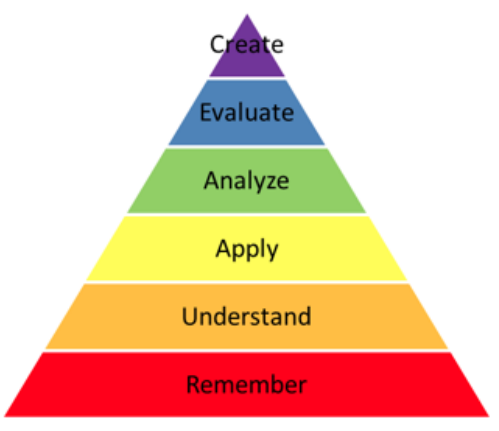

Bloom's Revised Taxonomy of Educational 


\section{Objectives}

- Given colored markers, students will apply their understanding of drawing in order to create a conceptual drawing of their dream house.

- Given colored markers, students will create architectural drawings from an inherent understanding of color.

- Given information on different architectural styles, students will consider their inner world and what would characterize their dream house and apply these characterizations to their drawings.

\section{Daily Objectives/Essential Question:}

What would your dream house include?

Why did you choose the colors you did?

What details are your favorite in your drawing, and why?

What do you like about the drawing process?

Assessment Criteria: Below, is a detailed rubric of how each student's artistic production will be assessed:

\begin{tabular}{|c|c|c|c|}
\hline & Distinguished & Mastery & Novice \\
\hline $\begin{array}{l}\text { OBJECTIVE } 1 \\
\text { Technical Skill }\end{array}$ & $\begin{array}{l}\text { The student } \\
\text { has } \\
\text { incorporated } \\
\text { multiple } \\
\text { architectural } \\
\text { styles, colors, } \\
\text { and details in } \\
\text { their drawing. }\end{array}$ & $\begin{array}{l}\text { The student } \\
\text { incorporated } \\
\text { at least two } \\
\text { architectural } \\
\text { elements in } \\
\text { their drawing. } \\
\text { There are at } \\
\text { least two } \\
\text { different } \\
\text { colors used in } \\
\text { the drawing, } \\
\text { and a few } \\
\text { details. }\end{array}$ & $\begin{array}{l}\text { The student } \\
\text { does not } \\
\text { show } \\
\text { multiple } \\
\text { elements of } \\
\text { architecture } \\
\text { in their } \\
\text { work, color, } \\
\text { or detail. }\end{array}$ \\
\hline $\begin{array}{l}\text { OBJECTIVE } 2 \\
\text { Formal Quality }\end{array}$ & $\begin{array}{l}\text { The student } \\
\text { creates a } \\
\text { dynamic }\end{array}$ & $\begin{array}{l}\text { The student } \\
\text { creates a } \\
\text { somewhat }\end{array}$ & $\begin{array}{l}\text { The student } \\
\text { does not use } \\
\text { much color }\end{array}$ \\
\hline
\end{tabular}




\begin{tabular}{|c|l|l|l|}
\hline & $\begin{array}{l}\text { drawing by } \\
\text { implementing } \\
\text { a wide variety } \\
\text { of color, } \\
\text { evoking } \\
\text { emotion and } \\
\text { deeper } \\
\text { elements of } \\
\text { the drawing. }\end{array}$ & $\begin{array}{l}\text { dynamic } \\
\text { drawing, } \\
\text { using some } \\
\text { color and } \\
\text { showing } \\
\text { understandin } \\
\text { g of how it } \\
\text { creates visual } \\
\text { interest } \\
\text { within a } \\
\text { work. }\end{array}$ & $\begin{array}{l}\text { in their } \\
\text { work, } \\
\text { perhaps } \\
\text { using only } \\
\text { one color in } \\
\text { order to } \\
\text { execute their } \\
\text { drawings. }\end{array}$ \\
\hline OBJECTIVE 3 & $\begin{array}{l}\text { The student is } \\
\text { able to } \\
\text { describe the } \\
\text { elements they } \\
\text { used to create } \\
\text { their dream } \\
\text { house in } \\
\text { incorporates } \\
\text { some } \\
\text { personal } \\
\text { elements in } \\
\text { understand the } \\
\text { "why" of what } \\
\text { they created. }\end{array}$ & $\begin{array}{l}\text { The student } \\
\text { does not } \\
\text { show an an } \\
\text { on of their } \\
\text { house. }\end{array}$ & $\begin{array}{l}\text { understandin } \\
\text { g of } \\
\text { incorporatin } \\
\text { g personal } \\
\text { elements } \\
\text { within their } \\
\text { work. }\end{array}$ \\
\hline
\end{tabular}


Teaching Resources Needed to Support the Lesson:

- Introduction and demonstration led by the teacher

- Architecture discussion

- Handouts:
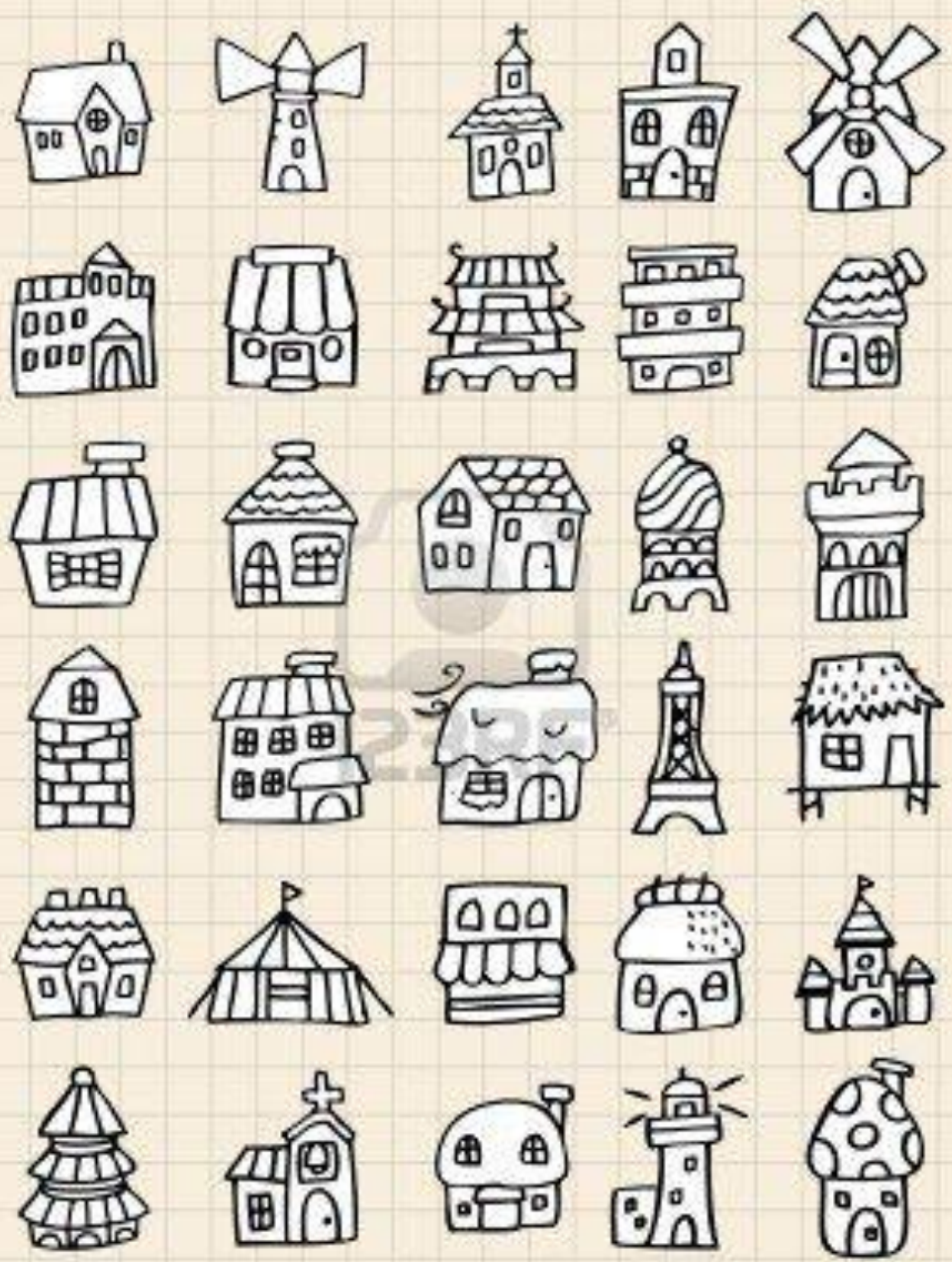


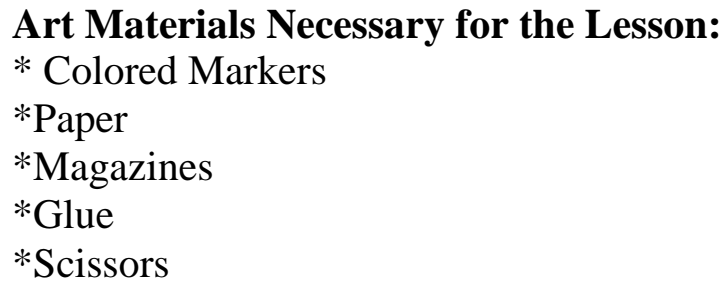

\begin{tabular}{|c|c|}
\hline $\begin{array}{r}\text { Teacher Activities } \\
\end{array}$ & Student Activities \\
\hline $\begin{array}{l}\text { Introduction: } \\
\text { The teacher will introduce the dream house art } \\
\text { project, as well as open a discussion about } \\
\text { architecture and discuss the different kinds of } \\
\text { architectural style to the students and present to } \\
\text { the students how to incorporate these elements } \\
\text { into their drawings. }\end{array}$ & $\begin{array}{l}\text { Given the architectural introduction, students } \\
\text { will begin work on their collages, to inspire } \\
\text { elements in their later drawings of their } \\
\text { "dream house." Students will become more } \\
\text { familiar with the components of architecture } \\
\text { and what makes a house unique. }\end{array}$ \\
\hline $\begin{array}{l}\text { Development: } \\
\text { The teacher will provide the students with }\end{array}$ & \\
\hline $\begin{array}{l}\text { magazines, glue, and scissors. The teacher will } \\
\text { then instruct the students to create a collage } \\
\text { about elements that appeal to their senses, in } \\
\text { order to inspire their architectural drawings. }\end{array}$ & $\begin{array}{l}\text { Students will then begin to create drawings of } \\
\text { their dream houses using colored markers and } \\
\text { paper, in order for students to explore the } \\
\text { elements of color, line and shape. Students } \\
\text { will become more so familiar with these }\end{array}$ \\
\hline $\begin{array}{l}\text { The teacher will then provide each student with } \\
\text { colored markers and paper and instruct them to } \\
\text { draw a dream house, fully actualized with detail, }\end{array}$ & $\begin{array}{l}\text { elements through the creation of their } \\
\text { individual houses. }\end{array}$ \\
\hline color, and shape. & $\begin{array}{l}\text { Students will analyze and discuss their } \\
\text { drawings as they are created. This will provide }\end{array}$ \\
\hline $\begin{array}{l}\text { The teacher will ask essential questions in order } \\
\text { to inspire creativity and production in the } \\
\text { students. }\end{array}$ & $\begin{array}{l}\text { the students with more personal and peer- } \\
\text { based knowledge of what they have created, } \\
\text { and why they have created it. }\end{array}$ \\
\hline \multicolumn{2}{|l|}{ Conclusion: } \\
\hline $\begin{array}{l}\text { The teacher will instruct the students to describe } \\
\text { the elements of their dream house and reflect on } \\
\text { their creation with their peers. This will allow } \\
\text { the students to describe what they have learned } \\
\text { through their artistic processes, and expose them } \\
\text { to the artistic processes of the other students. }\end{array}$ & $\begin{array}{l}\text { Students will conclude the lesson by explaining } \\
\text { the dream house that they created, and why the } \\
\text { visual elements they incorporated, are } \\
\text { important. This will help students to understand } \\
\text { the importance of creating art and the } \\
\text { opportunities that are made available of self- } \\
\text { discovery. }\end{array}$ \\
\hline
\end{tabular}




\section{Critical Comments and Reflections:}

In preparation of this lesson, I purposefully chose a closed objective lesson. While the students were given the opportunity to incorporate personal elements within their dream house, they were only given a limited amount of creative tools (i.e., colored pencils and paper, magazines, glue, and scissors), thus the production by each student, was relatively similar in terms of visualization. Children at this age are just able to recreate their worlds in a "realistic" sense, and often choose to do so-abstract thinking, so to speak, has thus left the child momentarily (thinking of early childhood, often rearing a wide variety of abstraction, due to decreased motor control and logical conception) for a more concrete, rooted-in-reality artistic reproduction. While the students were given the instruction to create a "dream" house, their drawings primarily depicted traditional reproductions of houses created at the elementary level. During the next lesson plan, the students will be given free range in their art making, and I will study the effects this has on their creativity. 


\subsection{Chapter 4}

\subsection{Data Collection}

The artwork created during this closed-curriculum activity, resulted in relatively visually similar images. Even with the encouragement of creating a dream house, the children ultimately created drawings that were very similar to one another. This shows me, that the standardized mentality of education at the elementary level is very real. During a time that students can learn anything, we have chosen to encourage them to conform, and to create "correctly." Thus, students who are incredibly creative and imaginative are slowly but surely losing touch with the skill, throughout their education, to create intuitively and uniquely. Instead, even within a subjective discipline, students are creating through means of formality and comfortability. The students, while compliant, were not necessarily excited by this project. While they enjoy drawing, they do not seem to form a personal attachment to this work, nor do they always remember which work is theirs at first glance, several weeks later. To me, these are indicators to a lack of creative flow, growth, and enjoyment of manipulation of materials. Below, you will find the work created by the students during the process of this project. 

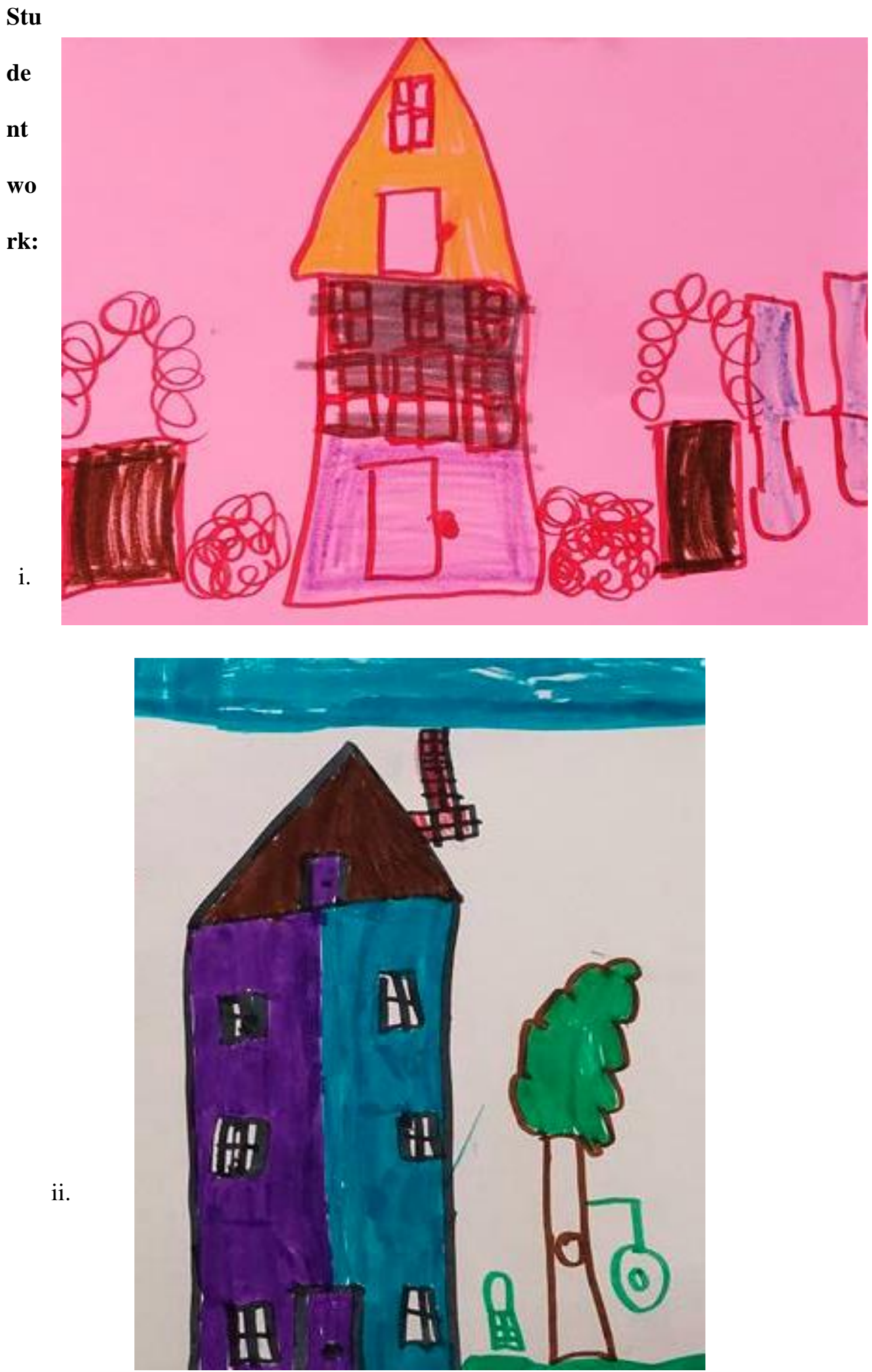

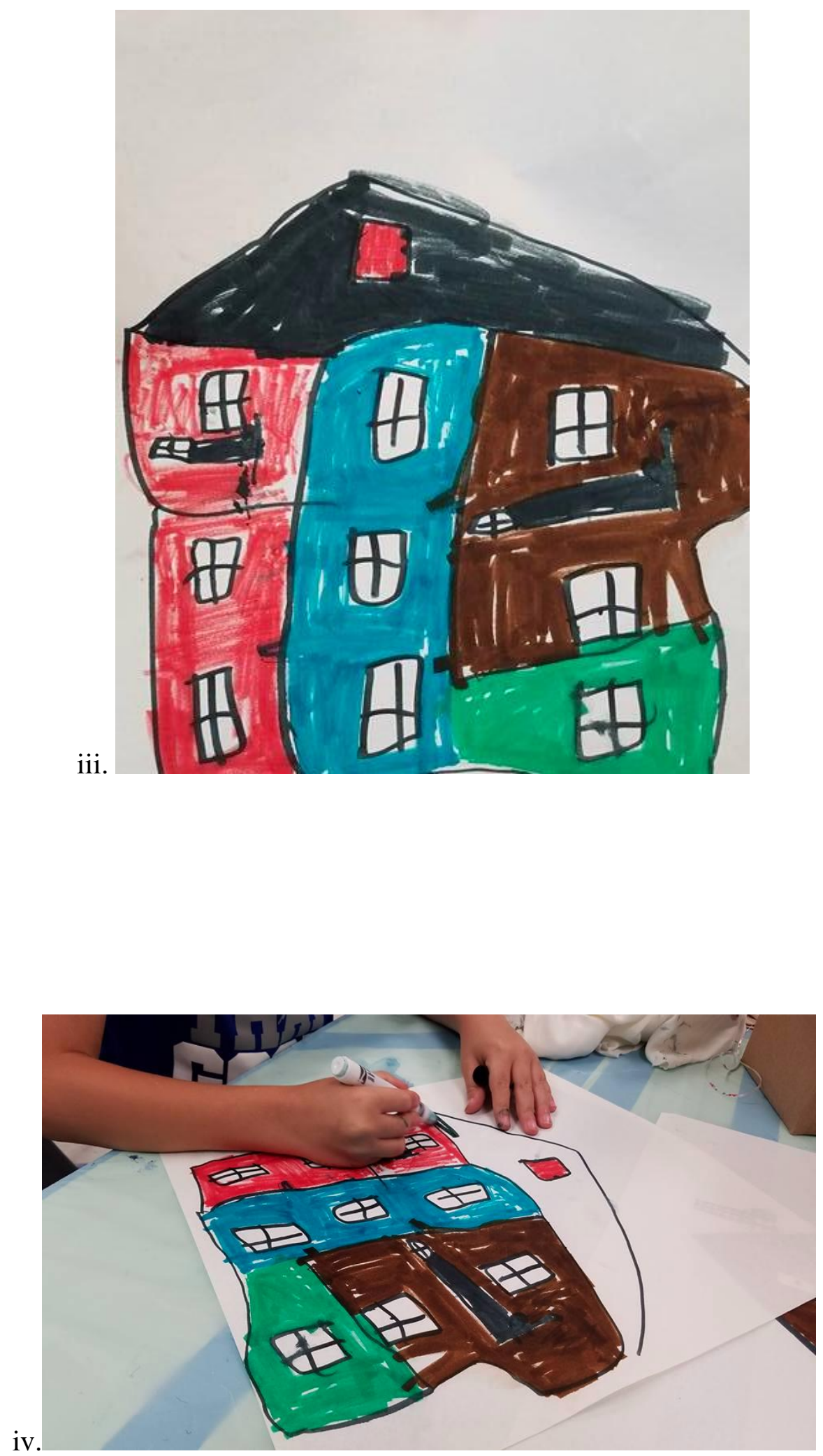


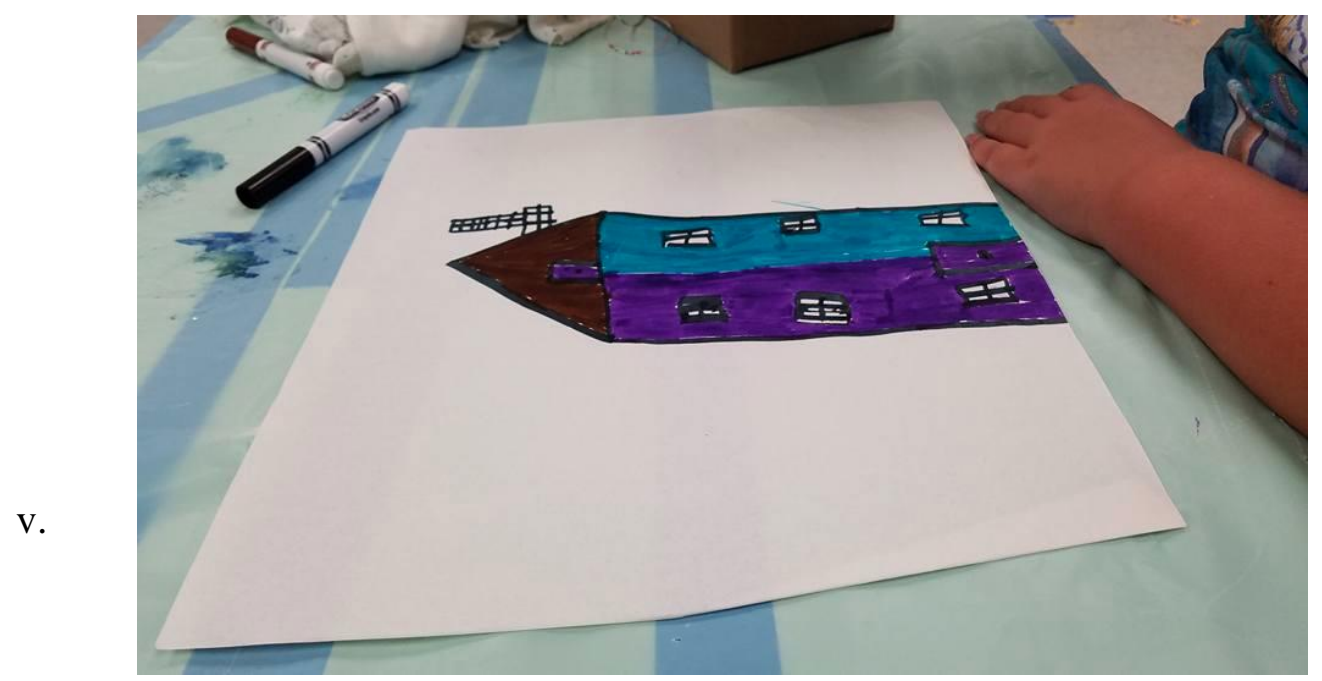


The second lesson plan given to the students was crafted with the open-ended art curriculum in mind. During this lesson, the students were introduced to the concept of found object art. For this project, I encouraged the students to create from the materials they were given. I encouraged them to create freely, openly, and to seek inspiration from materials at hand. What does this piece of lace remind you of? A curtain? A cloud? Your grandmother's house? The students were instructed to create from their own individual thought. During the creative process of this project, several of the students remarked on what fun they were having, and varying approaches they discovered through the objects at hand excited them. The students were told they could utilize any material or object that was available, and they were given access to shelves that were fully stocked with found objects and other varying art materials. Through access to open-ended creative process and the encouragement of the usage of alternative art making materials, the highly innovative and creative young students approached this project with vigor and youthful enthusiasm. 


\section{Lesson Title: Creating With Found Objects! Grade Level: $2^{\text {nd }}$}

Skills: During this lesson, students will be introduced to the world of found object art, and given free reign to create. Students will create from their mind's eye, so to speak, and be instructed to create from the found objects provided. What they create, will be up to them, thus probing them to create inherently, and from what the objects inspire them to create.

Social Studies Standards People, Places, and Environments - the relationship between humans and the physical world.

WV Visual Arts CSO: VA.S.2.1 Students will:

- identify media and materials used in creating art;

- understand processes and techniques in creating art;

- apply problem-solving skills in creating two-dimensional and three-dimensional works of art; and

- use materials and tools in a safe and responsible manner.

National Visual Arts Standards:

Connecting - Relating artistic ideas and work with personal meaning and external context.

* Anchor Standard \#10. Synthesize and relate knowledge and personal experiences to make art.

* Anchor Standard \#11. Relate artistic ideas and works with societal, cultural and historical context to deepen understanding.

\section{Overall Lesson Objective:}

- Students will create from their surrounding visual culture with found objects. The subject matter of their work will be entirely up to them. I want the students to take away from this lesson, artistic freedom and the ability to create independently. 


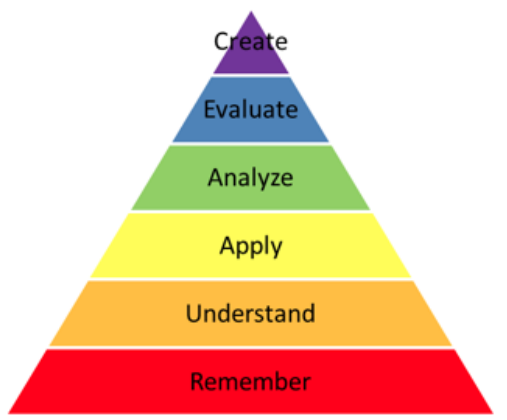

Objectives
Bloom's Revised Taxonomy of Educational

- Students must create dynamic works of art utilizing found objects.

work.

- Applying the usage of texture, students will create visual interest in their

- Students must analyze their visual culture, and utilize the found objects to create conceptually individual works of art

\section{Daily Objectives/Essential Question:}

What do these objects remind you of?

What do you think you will create from the objects?

What do you like about the textures of these objects?

What do you like about creating from found objects, opposed to more traditional art making practices, like drawing?

Assessment Criteria: Below, you will find assessment criteria for the found object art

\begin{tabular}{|c|l|l|l|}
\hline & Distinguished & \multicolumn{1}{|c|}{ Mastery } & \multicolumn{1}{|c|}{ Novice } \\
\hline OBJECTIVE 1 & $\begin{array}{l}\text { Students } \\
\text { create large } \\
\text { works of art } \\
\text { using found } \\
\text { objects. The } \\
\text { work has } \\
\text { multiple } \\
\text { components. }\end{array}$ & $\begin{array}{l}\text { The student } \\
\text { uses found } \\
\text { objects to } \\
\text { create a piece } \\
\text { of found } \\
\text { object art, } \\
\text { using at least } \\
\text { five objects. }\end{array}$ & $\begin{array}{l}\text { The student } \\
\text { does not } \\
\text { seem to } \\
\text { show } \\
\text { apparent } \\
\text { understandin } \\
\text { g of creating } \\
\text { a free-range } \\
\text { art project } \\
\text { using found } \\
\text { objects. }\end{array}$ \\
\hline OBJECTIVE 2 & $\begin{array}{l}\text { The student } \\
\text { incorporates } \\
\text { multiple } \\
\text { textures, } \\
\text { objects, and } \\
\text { details in their } \\
\text { work. }\end{array}$ & $\begin{array}{l}\text { The student } \\
\text { incorporates } \\
\text { some } \\
\text { textures, } \\
\text { objects, and } \\
\text { details in } \\
\text { their work. }\end{array}$ & $\begin{array}{l}\text { incorporate a } \\
\text { multitude of } \\
\text { textures, } \\
\text { objects, or } \\
\text { details in }\end{array}$ \\
\hline
\end{tabular}




\begin{tabular}{|c|c|c|c|}
\hline & & & their work. \\
\hline $\begin{array}{c}\text { OBJECTIVE } 3 \\
\text { Conceptual Complexity }\end{array}$ & $\begin{array}{l}\text { The student } \\
\text { creates an } \\
\text { original piece } \\
\text { of found } \\
\text { object art with } \\
\text { a complete } \\
\text { narrative. }\end{array}$ & $\begin{array}{l}\text { The student } \\
\text { creates a } \\
\text { dynamic } \\
\text { work of art } \\
\text { with some } \\
\text { understandin } \\
\text { g of a } \\
\text { narrative for } \\
\text { the work. }\end{array}$ & $\begin{array}{l}\text { The student } \\
\text { does not } \\
\text { incorporate a } \\
\text { narrative } \\
\text { with their } \\
\text { work. }\end{array}$ \\
\hline
\end{tabular}

Teaching Resources Needed to Support the Lesson: Note: All background materials, research documents, and handouts should be listed below and included as attachments.

- PowerPoint about found object art

- Handouts

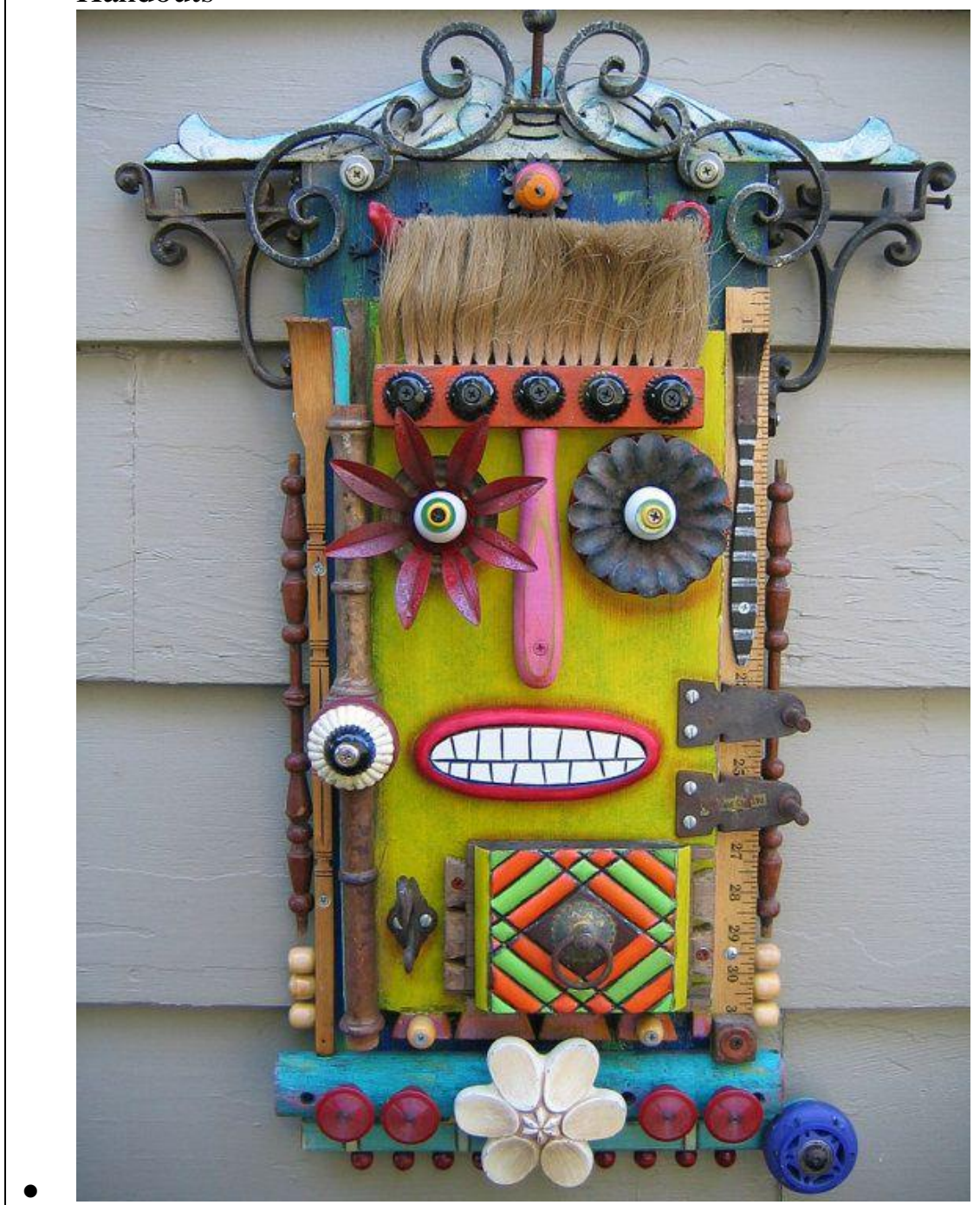




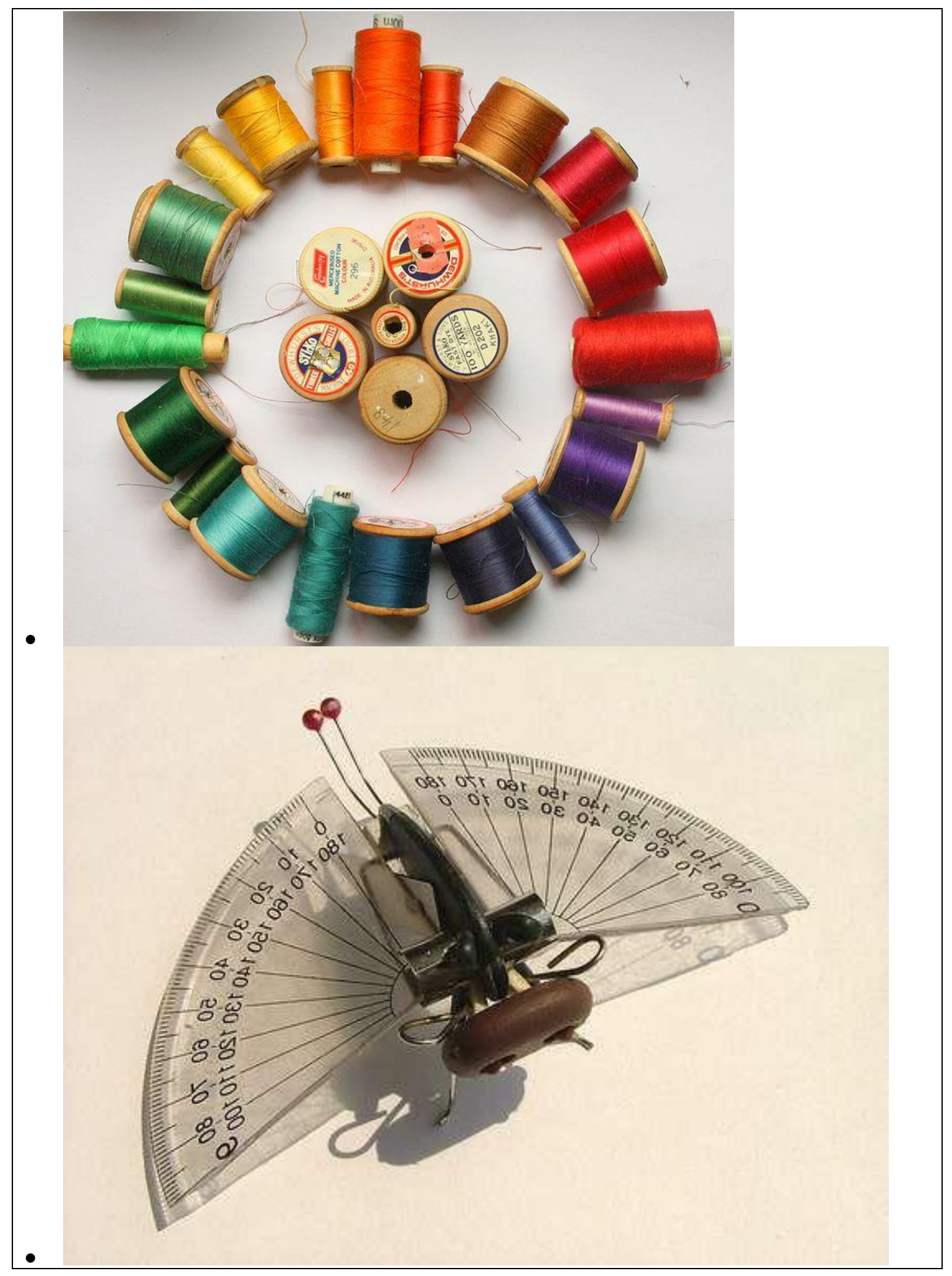




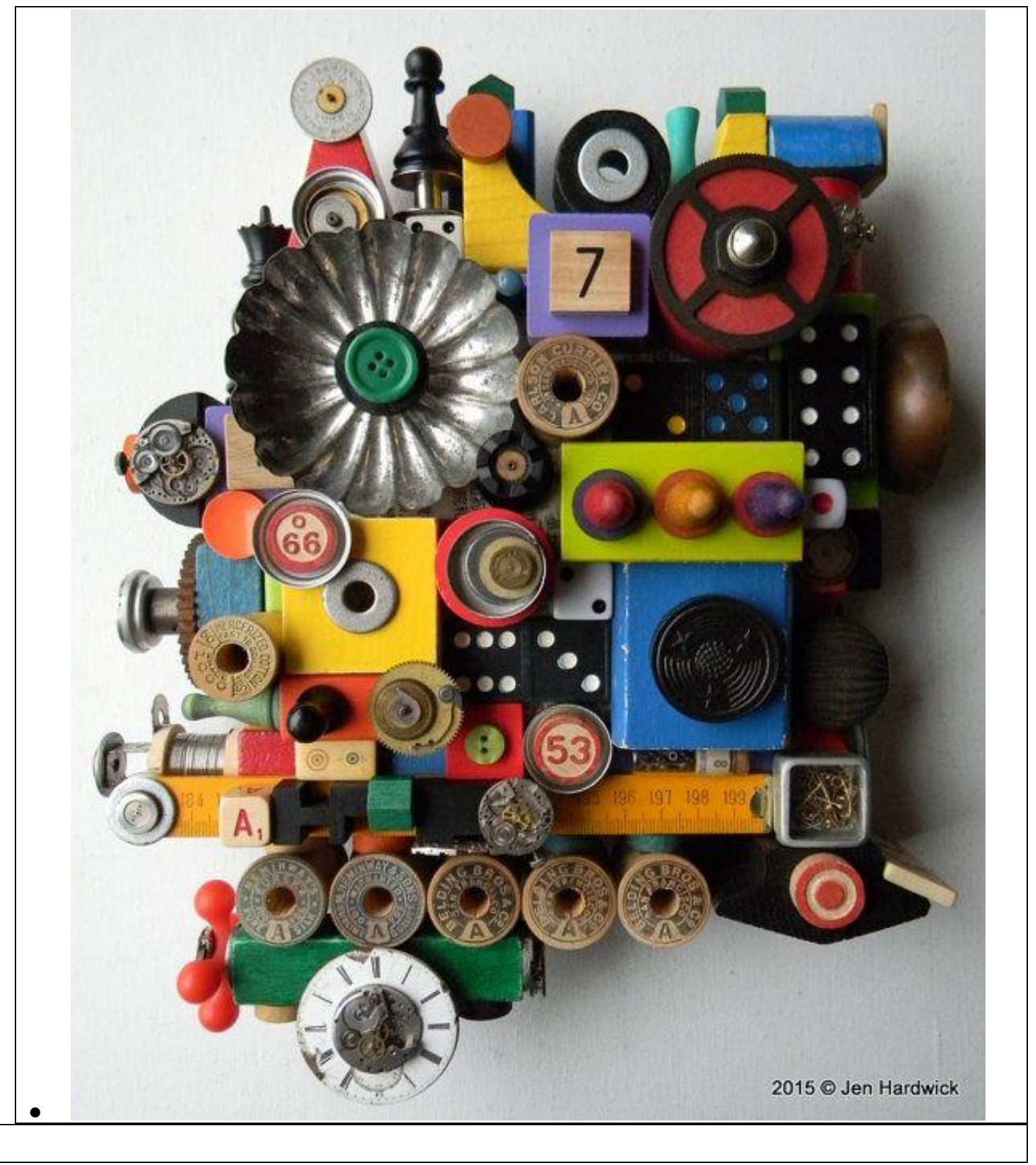

\section{Art Materials Necessary for the Lesson:}

- Found objects

*Glue

*Fabric

*Glitter

* Paint

* Markers

*Paper 


\begin{tabular}{|c|c|}
\hline Teacher Activities & Student Activities \\
\hline $\begin{array}{l}\text { Introduction: } \\
\text { Teacher will introduce lesson with a discussion } \\
\text { on the found object art movement. The teacher } \\
\text { will also present the students with images } \\
\text { showing a variety of found art productions. }\end{array}$ & $\begin{array}{l}\text { Students will analyze the found objects } \\
\text { given to them, and from the objects } \\
\text { create their narrative. Students will } \\
\text { gain the crucial ability to create } \\
\text { abstractly and intuitively. }\end{array}$ \\
\hline $\begin{array}{l}\text { Development: } \\
\text { The teacher will ask essential questions in order } \\
\text { to allow students to think about the visual } \\
\text { culture that surrounds them. From that visual } \\
\text { culture, the teacher will instruct the students to } \\
\text { investigate the found objects and art materials } \\
\text { presented to them. What do they remind you of? } \\
\text { What can you create from these objects? }\end{array}$ & $\begin{array}{l}\text { The students will create found art projects in } \\
\text { order to exhibit their creativity and to } \\
\text { explore their personal interpretation } \\
\text { and usage of objects presented to } \\
\text { them. } \\
\text { Students will create from the found objects } \\
\text { and art materials provided to them. } \\
\text { They will create a narrative that goes } \\
\text { along with the work that they have } \\
\text { created. This will explore the creative } \\
\text { voices and individuality of the } \\
\text { students. }\end{array}$ \\
\hline $\begin{array}{l}\text { Conclusion: } \\
\text { The teacher will conclude the lesson by } \\
\text { encouraging the students to describe the } \\
\text { narratives behind each of their works of art. }\end{array}$ & $\begin{array}{l}\text { The students will conclude the lesson by } \\
\text { discussing their work with their peers. } \\
\text { They will do this to explore the } \\
\text { meaning of their work and the } \\
\text { meaning of the work of others. } \\
\text { Through this discussion, students will } \\
\text { discover why the create the things that } \\
\text { they do, and how to attach meaning to } \\
\text { their artwork. }\end{array}$ \\
\hline
\end{tabular}

\section{Critical Comments and Reflections:}

The students responded very positively to this method of art making, and had a lot of fun innovating and creating the stories that attached to their individual artwork. Each student in the small group remarked that they enjoyed creating with the found objects more so than simple drawing methods. The enjoyment of this method showed through the sheer amount of time spent on each artwork, and the care each student showed these works. Interestingly, the students wanted to revisit the "dream house" lesson plan, and create a house using found objects and paint. The students spent much longer creating this house, and wanted 
to of their own volition. They spent much of the summer sitting in the house, and incorporating it into their day, showing that they were, indeed, proud of their creation. 
The artwork created during the process of this project was highly innovative, unique, and indicative of the individual differences and creative processes of the students at hand. The students showed ownership of this project and grew attached to the things that they created. One boy became very emotional when he thought another student had accidentally destroyed his project. While we were able to fix it, this boy's emotional response to his project showed the amount of care he had exerted in the creation of it. Tears were not shed over the drawing project, and many of them were not even taken home at the culmination of the project. During the course of these two projects, it was clear which one the students preferred and which project yielded more creative innovation and thought. In the art classroom, it is important to leave the classroom fluid, and open to invention, especially during the developmental years. These kinds of art projects allow for the young mind to remain intact creatively, and allow imaginative creations to span their art-making career within the art classroom. The images of the student work created during this project are listed below. 
Student work:

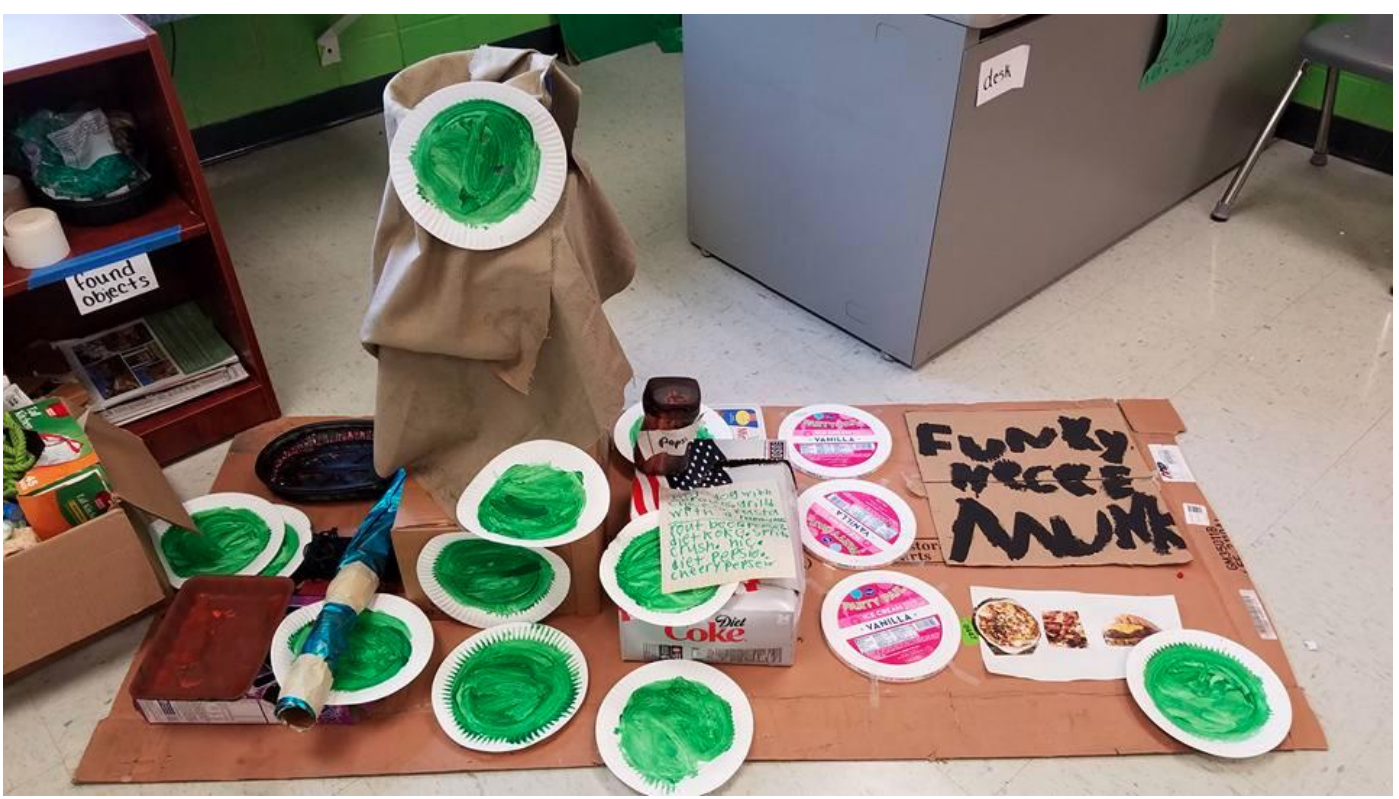

vii.

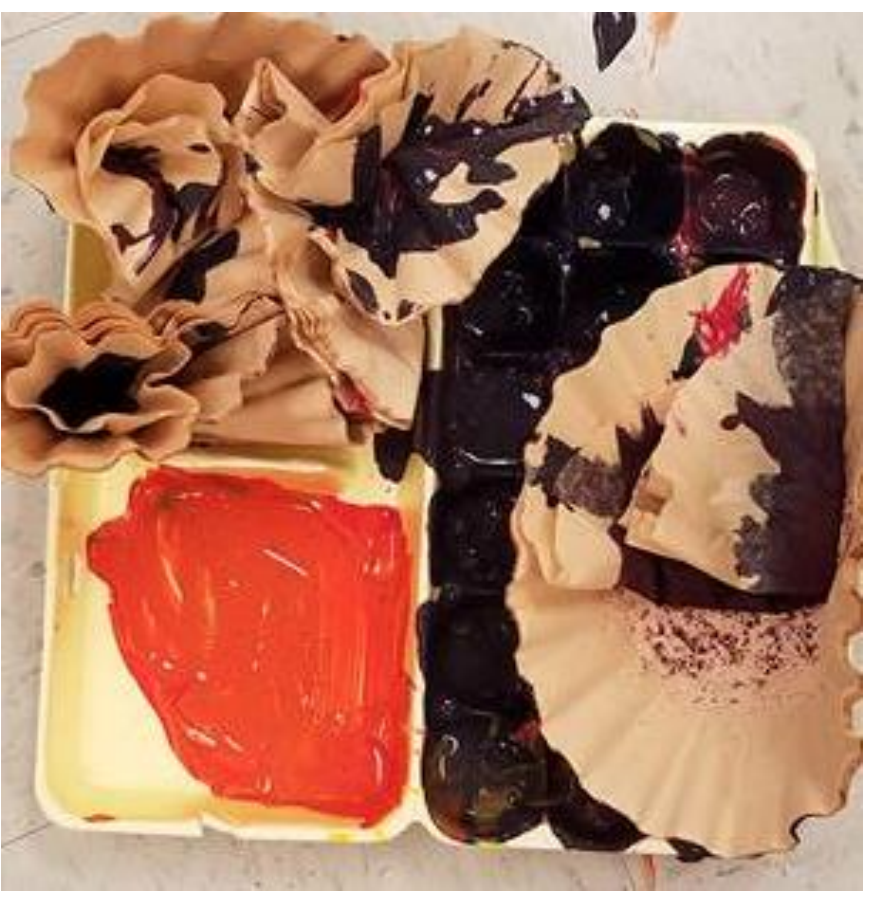




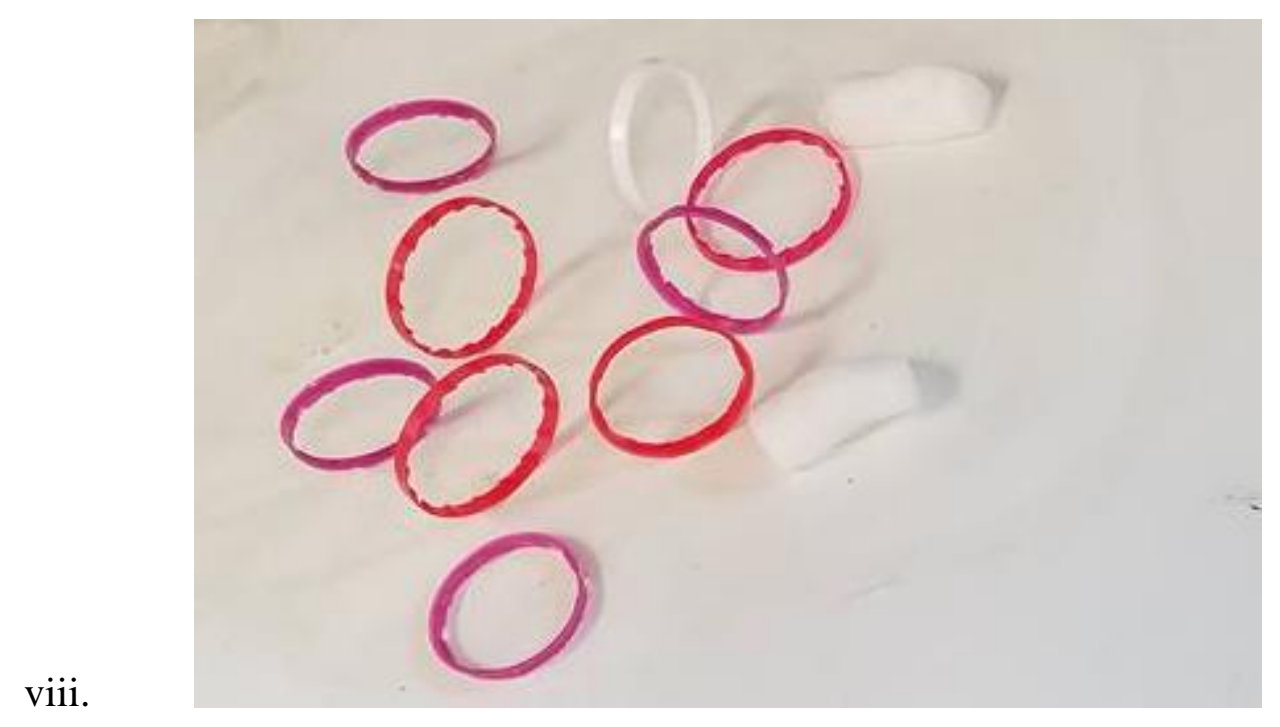

ix.

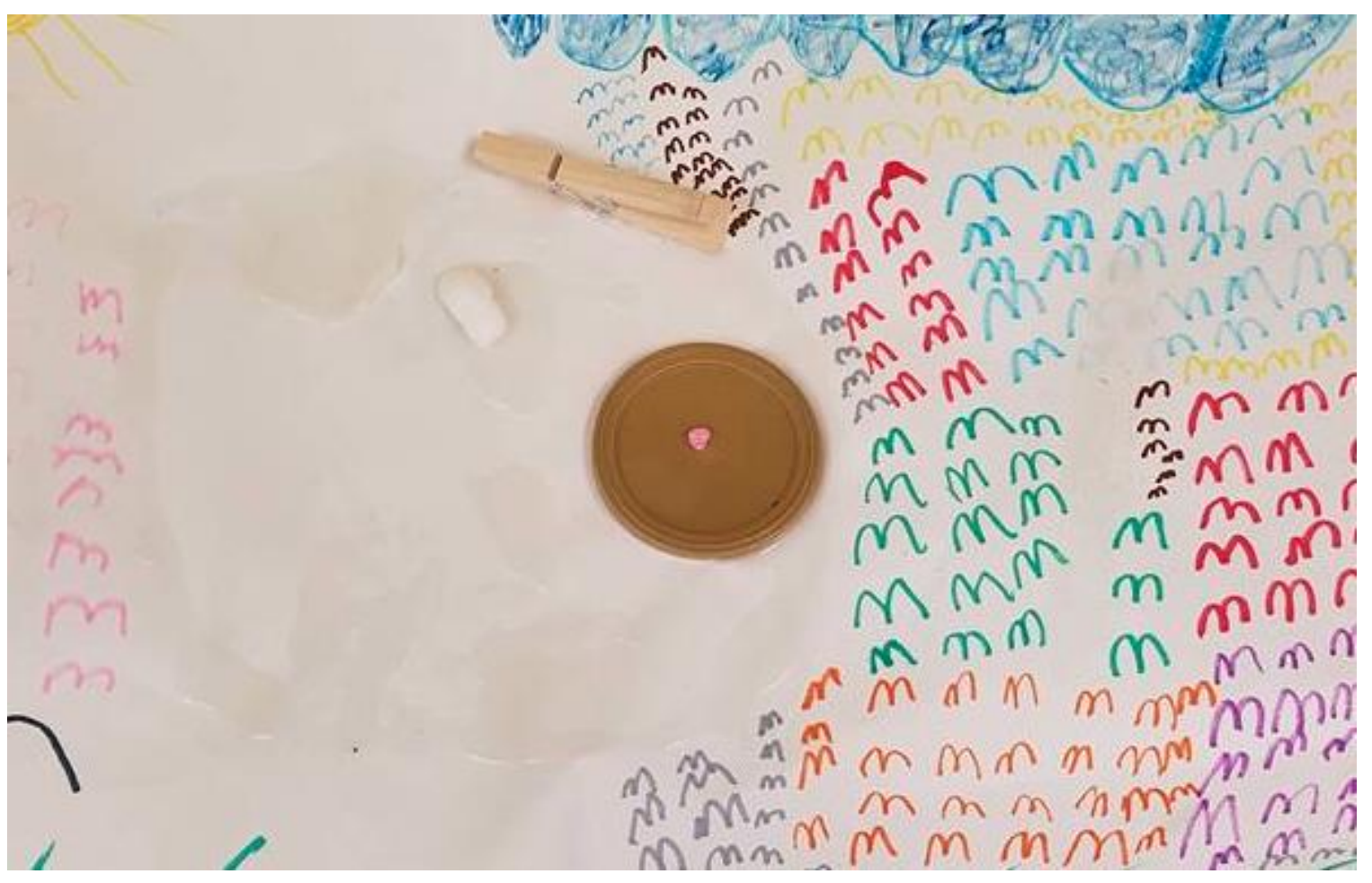


One interesting thing that occurred after each of these projects had been introduced was that the students started to revisit the "dream house" concept on their own accord. After constructing with found objects, the students felt personally inspired to create additional houses for the classroom. House structures that they took pride in and that they wanted to remain displayed in the classroom for the entirety of their time there. This revisits the idea of the hidden curriculum. Hidden curriculum refers to the unwritten, unofficial, and often-unintended lessons, values, and perspectives that students learn in school. Without me prompting them, the students were inspired to create innovatively and personally. They really amazed me and made me proud. This age group is so susceptible to creativity; it is a shame to teach it away through a standardized mindset. The students created two "houses." One was an entirely abstracted structure created on the ground from multiple loops of yarn and tape. The students put their whole being into this creation. It took a relatively lengthy amount of time to create, as well as physical labor. The other house that the students created was from a large piece of cardboard, paper, and paint. The students created a hangout complete with a house structure with a driveway in front. It was fascinating to watch them revisit the initial dream house project with the progressed knowledge of found object art. When allowed, even elementary students can be innovative, thoughtful, and self-disciplined.

\section{Artist Action Panel to Judge Student Creativity}

To answer research question 1, does an open-ended curriculum inspire creativity within students, I assembled a group of art educators, practicing artists, and professors to judge the creativity of one image of production from each of the lesson plans. These individuals were simply prompted with the question of which image they found to be more 
creative, and why. They were not exposed to the purpose of the study, nor were their opinions influenced in any way. The images they were shown were:
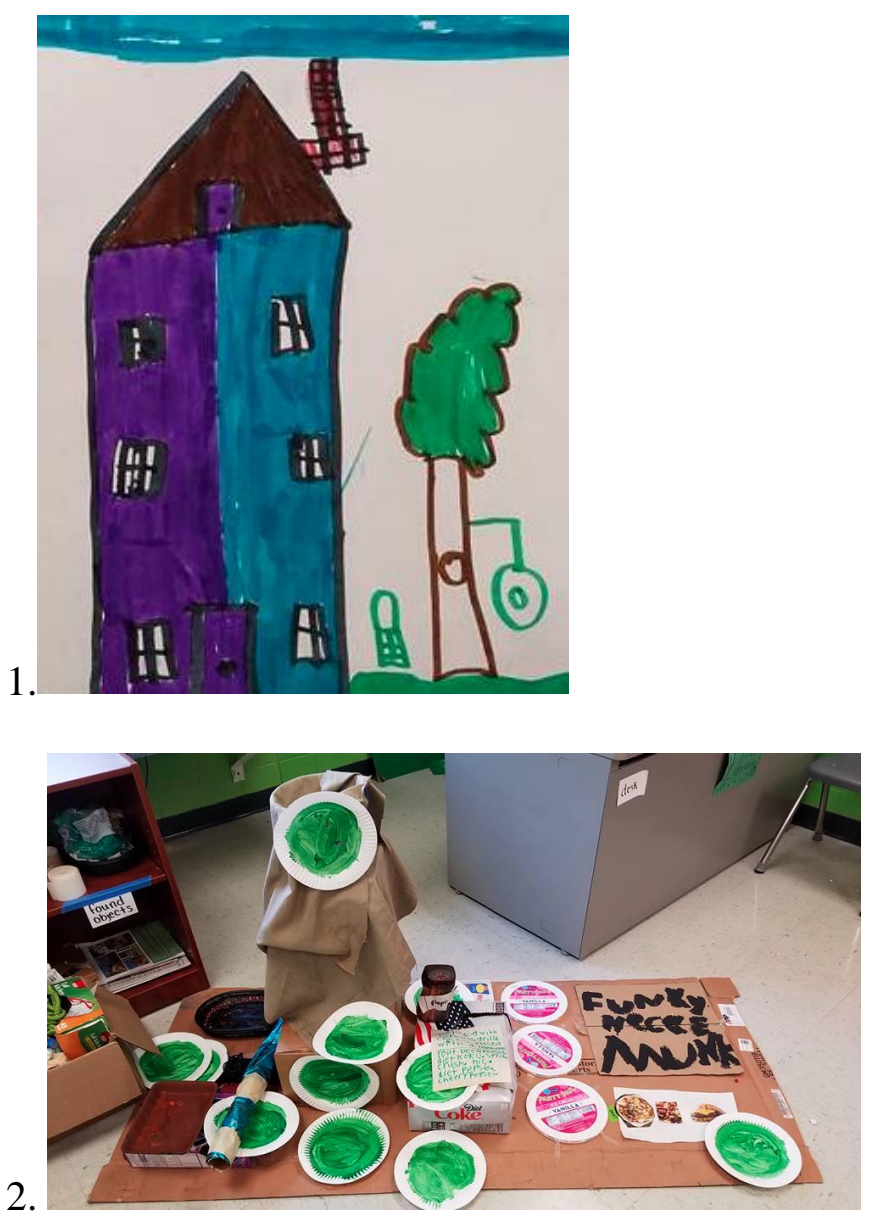

Of the individuals who responded, $75 \%$ found the second image, or the open-ended product, to be the most creative and innovative. One educator found the found object product to be more creative because it uses materials outside of the schema of "art materials" to express an idea.

Another practicing artist and educator also expressed a preference for the openended production. He states, "I'm more interested in the one on the bottom. It makes me curious. I find the one on top more pleasing to look at. 
The one on the bottom intrigues me (the open ended image). I want to talk to the kid about it but I'm hesitant to say it's the more creative of the two. I think for me to evaluate creativity I rely on some sense or some understanding of the process that created it. To me creativity is tied to a decision making process. It comes in response to situations, materials, and experience. Just by looking I don't feel like I can say much about the creativity of the bottom one. I want to know how materials were selected, if he or she was working with some sort of timeframe. Is there a starting point this creation came from? This is a kid I want to listen to."

Only after he inquired about the process was he informed the aims of both the open ended and closed curriculums. He then expressed a preference for the open-ended project, and also found it to be the more creative of the two. He expressed an interest in not just the product, but the process of the product presented in the image. Through his observations, he has captured an integral part of the education experience. That there is importance in the creative process of students, and it is often within the process that we find the most innovative and creative thoughts occurring. When students are allowed to creative expressively and personally, deeper connections are made in their art making, and a multitude of solutions are considered.

Two other art educators engaged in a discussion about the process, as well, and came to the conclusion that the open-ended project was the more creative of the two due to the narrative developed by the students who created it. Collectively, they came to the conclusion that it was a restaurant from what they concluded about the materials being used. They then created menus and a name for the restaurant from this decision. Overall, 
this was a very creative project that allowed for the students to let their imaginations run wild.

One art educator found the drawing to be more creative, however, due to the openended image not making visual sense to her. In her own opinion, the drawing was more creative because it was visually recognizable and made sense to the viewer. To the viewer, the open-ended example was somewhat disorganized and chaotic, and not easy to analyze.

Overall, the open-ended student work was received as being more creative and thought provoking, aligning with my hypothesis that an open ended art curriculum would lend itself to more creativity and productivity of students. While there was a panelist that disagreed with my findings, it is not abnormal for artwork to be chaotic, or disorganized. After all, great artwork makes individuals feel any variety of emotions and come to varying visual conclusions. Thus, I feel that while an artwork may very well be perceived as disorganized or chaotic, this does not necessarily mean that the work is uncreative, in fact it may be more creative than the work perceived as the more creative work. As discussed earlier, many students to do not see the value in their own work if it doesn't look like the example that they are presented with, or if it does not exist within realistic or formalistic parameters. Often, art educators realize the value in this work when the student does not. Art is a subjective discipline, so it is expected that differences of thought occur. 


\section{Student work:}

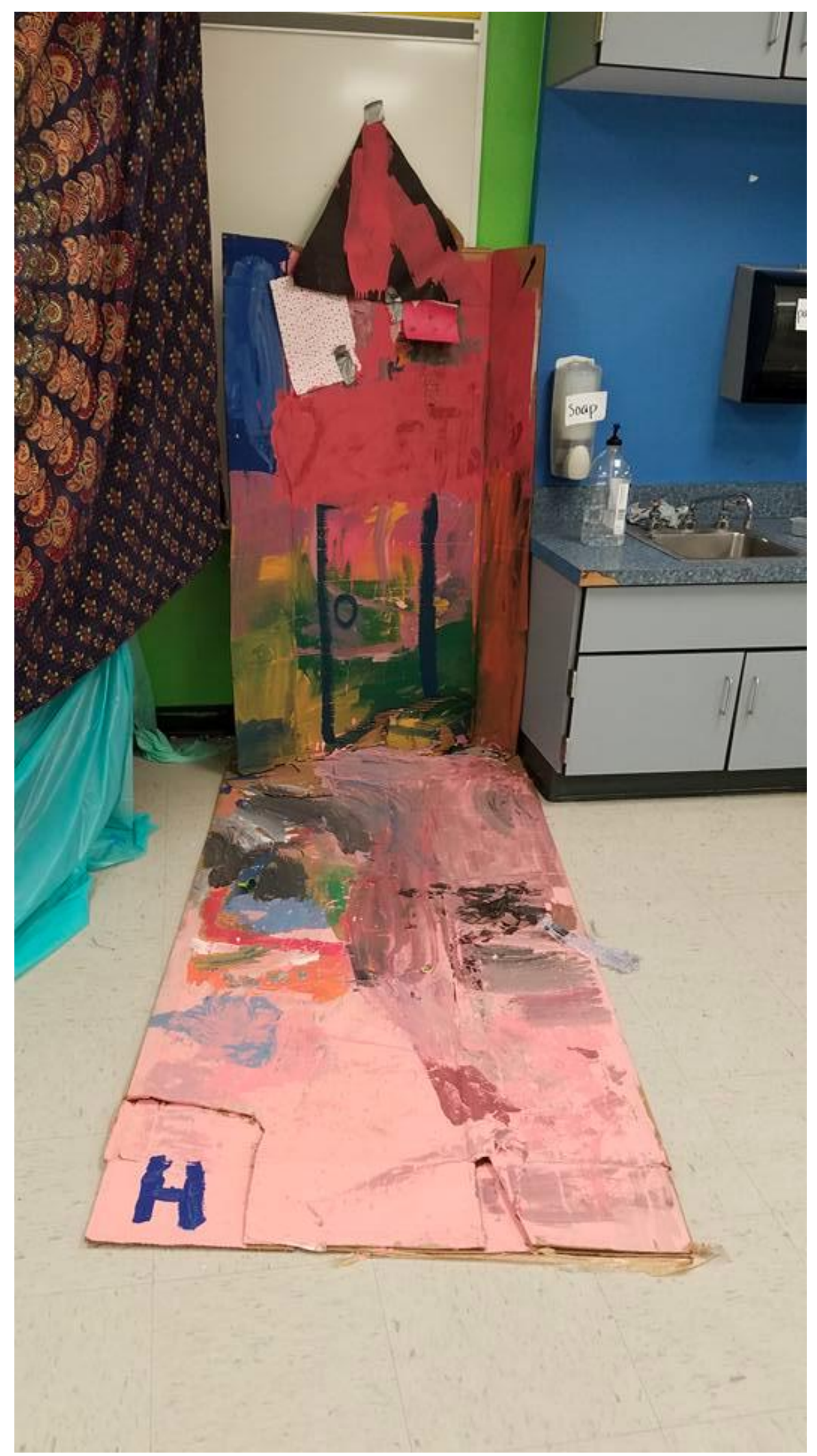




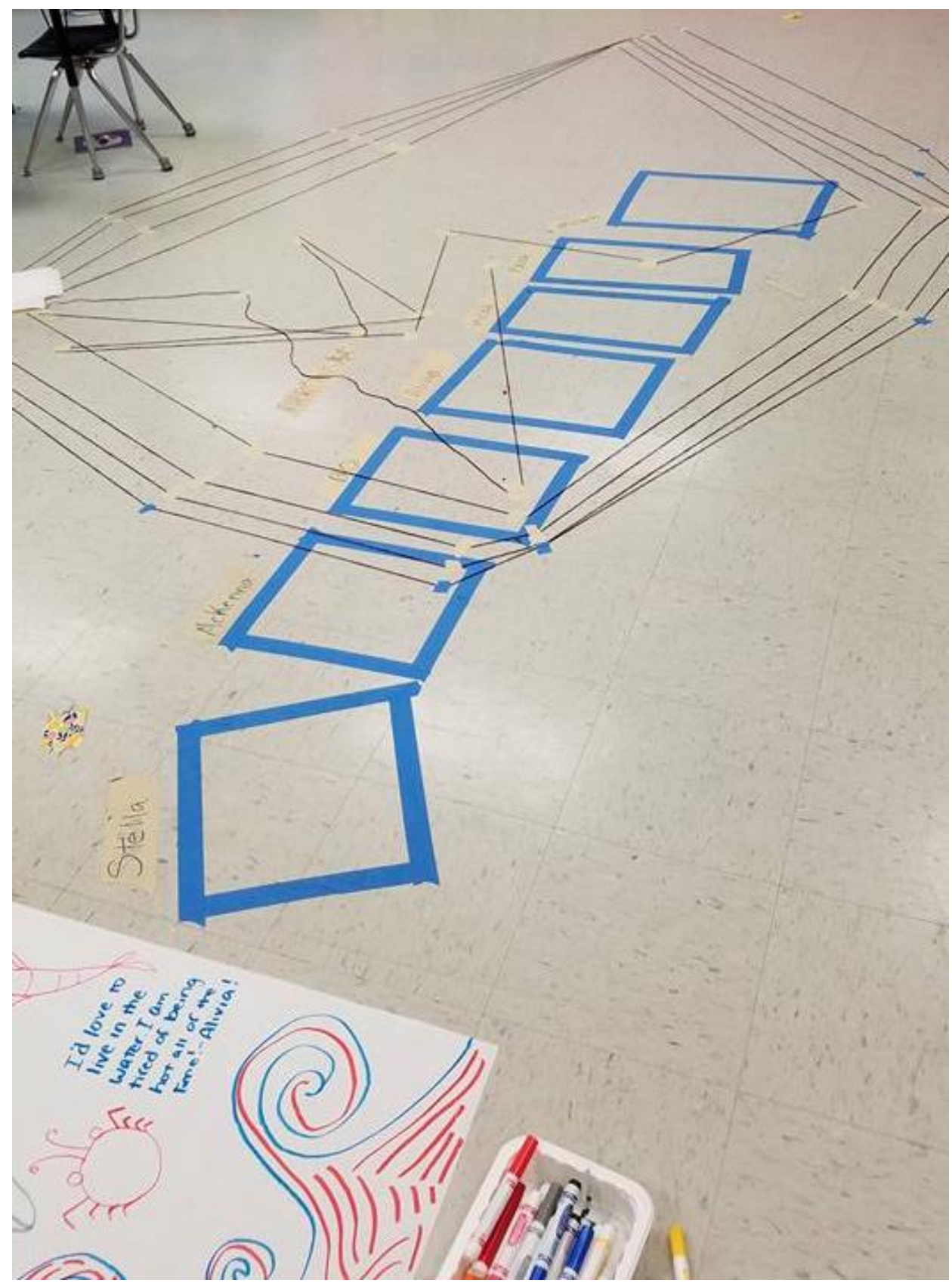




\subsection{Data Analysis}

5.1. My findings appear to suggest that an open-ended curriculum within the art education classroom is beneficial to student growth. Through my own observations, I found that the students were more excited by open-ended means of creation, they took more ownership of their work, and they worked more passionately. In my opinion, it is a disservice to not allow elementary age students to access their unique, imaginative, and at times bizarre perceptions of their visual world and their methods of creation. If elementary age students are allowed to create fluidly, abstractly, and personally, I believe that an overall higher level of creativity and innovation will be maintained throughout the lifetime and throughout one's creative development. The panel of art educators and practicing artists that were interviewed preferred the production results of an open-ended curriculum, as discussed previously. Below, figure $x$. shows that $3 / 4$ of those interviewed preferred the production results of open-ended curriculum to the production results of closed curriculum.

The modes of creative production from the students were positively impacted by open-ended curriculum. It is clear, under the guidance of an open-ended curriculum, students produced more innovative and expressive work. Open-ended curriculum also positively impacted the null curriculum, as it inspired the students to create mixed-media work of their own accord, when considering the three-dimensional house the students created after being introduced to the open-ended project. When looking at the results of open-ended art curriculum, student production is more creative visually and conceptually than it is when created under a closed-curriculum model. 


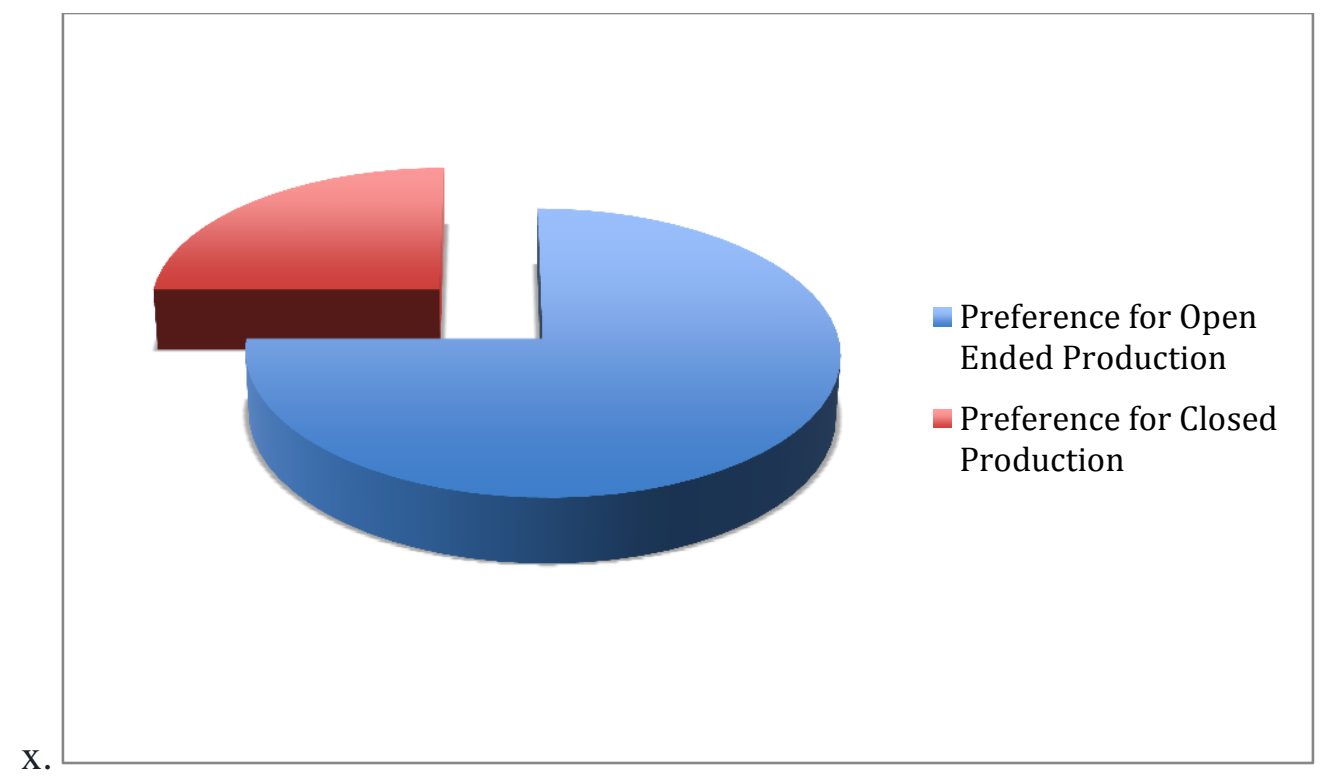

My findings appear to suggest that when open-ended curriculum was used the art product tended to be more innovative. Art educators and practicing artists that were questioned about the work created by the students in my study, primarily found the productions created during the implementation of the open-ended curriculum to be more creative and innovative in nature. This input relates to what I suspected to find through my research, gives merit to my thought that an open-ended approach to elementary art education will yield more creative results from the students. Overall, an open-ended art curriculum seemed to produce the most creative work in students. Students should be introduced to and familiar with formal and technical elements, however they should be given the freedom to create personally and deeply within the art classroom, in order to boost creativity throughout the individual's artistic career, and to generate the most complex and expressive art works.

\section{My findings appeared to suggest that open-ended curriculum inspires a variety of} methods of creation. During the closed-curriculum plan, each student drew a relatively similar depiction of a house, despite unique depictions of houses being acceptable. These 
examples, in my opinion, are not very distinguishable in their visual characteristics. During the open-ended plan, the students created a multitude of individual and group projects, many of them containing unique narratives and multiple working parts. Each work of art is unique, both visually and in materials used.

\section{My findings appeared to suggest that an open-ended curriculum does inspire}

thoughtful innovation. Given a variety of materials, the students used them in varying ways and interpreted them given their texture, original function, and the secular things they found the materials they used seemed to represent. Instead of creating what was "expected," the students created what they had uniquely envisioned. Instead of learning by seeing, the students learned by doing. They learned internally, they created from their inner worlds, which reflects in their products uniquely. Given the opportunity to create freely, the students responded innovatively.

\section{Recommendations}

My findings conclude that an open-ended curriculum does, in fact, increase creativity in elementary art students. My findings suggest that art educators should embrace an open-ended curriculum in order to promote the most individualistic, expressive work from their students.

\section{Future research}

Future research investigating open-ended curriculum in the elementary art classroom may find this study to be helpful. Researchers may wish to test these findings within a different sociocultural setting, age group, or context. Researchers aiming to support an open-ended curriculum may use this study to support the creative and innovative results an open-ended curriculum produces. 


\section{References}

Eisner, E. W. (2002). The Arts and the Creation of Mind. New Haven: Yale University Press.

Freedman, K.. (2003). The Importance of Student Artistic Production to Teaching Visual Culture. Art Education, 56(2), 38-43. Retrieved from http://www.jstor.org/stable/3194020

Freedman, K. J. (2003). Teaching visual culture: Curriculum, aesthetics, and the social life of art. New York: Teachers College Press.

Gardner, H. (1999). The disciplined mind. New York: Simon \& Schuster.

Gude, O. (2009). Art Education for Democratic Life. Art Education, 62(6), 6-11.

Gude, O.. (2010). Playing, Creativity, Possibility. Art Education, 63(2), 31-37. Retrieved from http://www.jstor.org/stable/20694822

Gude, O.. (2007). Principles of Possibility: Considerations for a 21st-Century Art \& Culture Curriculum. Art Education, 60(1), 6-17. http://doi.org/10.2307/27696187

Jackson, P. (1968). Life in classrooms. New York: Holt, Rinehart \& Winston.

Peterson, T. E. (2012). Constructivist Pedagogy and Symbolism: Vico, Cassirer, Piaget, Bateson. Educational Philosophy \& Theory, 44(8), 878-891. doi:10.1111/j.14695812.2011.00765.x

Read, H. (1958). Education through art. New York: Pantheon Books. RICHARDSON, J., \& WALKER, S. (2011). Processing Process: The Event of Making Art. Studies In Art Education, 53(1), 6-19.

Slattery, P. (1995). Curriculum development in the postmodern era. New York: Garland

Walker, S. (2015). Rethinkers. Studies In Art Education, 56(2), 99-102.

Walker, S.. (2004). Understanding the Artmaking Process: Reflective Practice. Art Education, 57(3), 6-12. Retrieved from http://www.jstor.org/stable/3194088 


\section{Permission Forms}

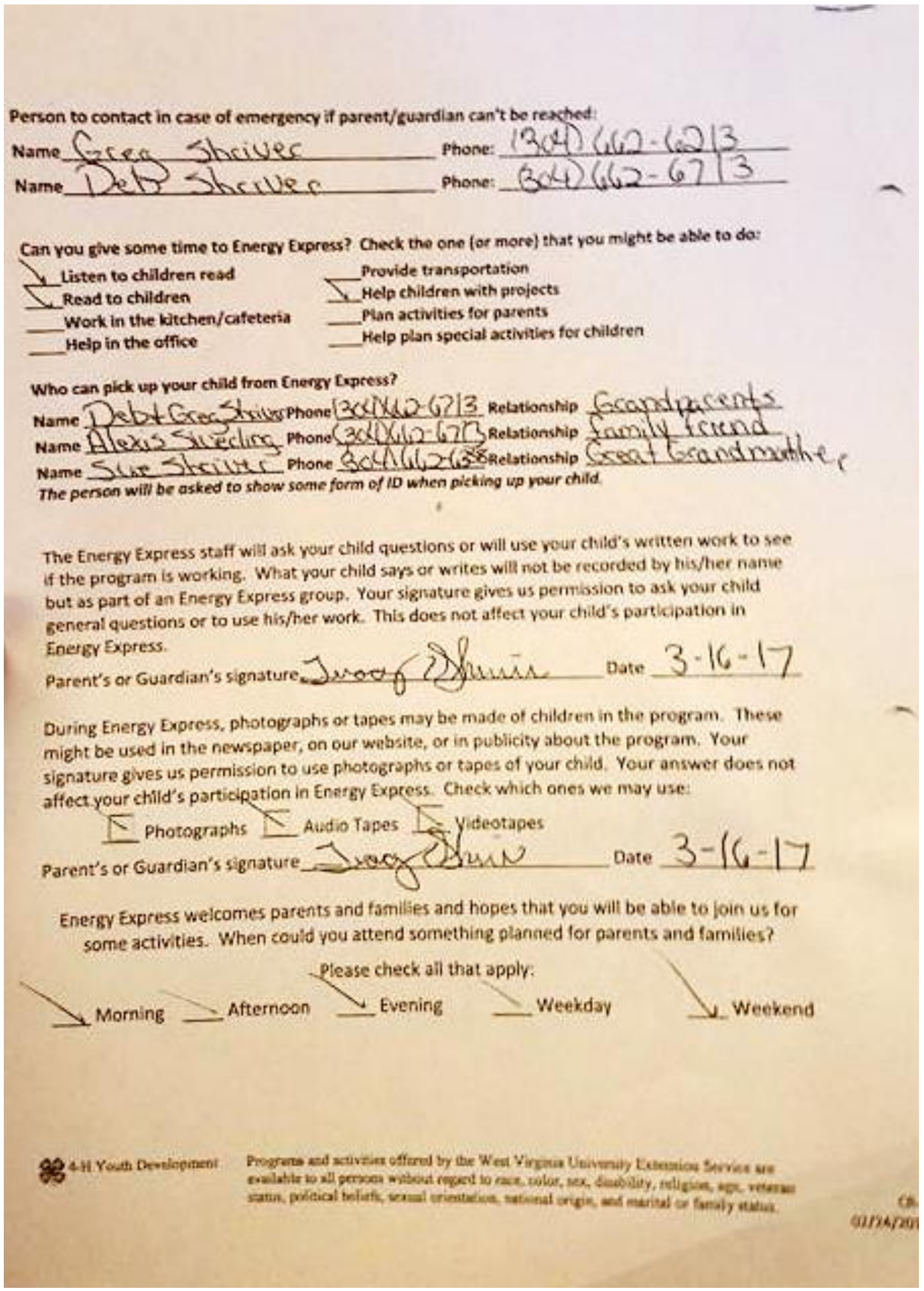




\begin{tabular}{|c|c|}
\hline vame Buddy Ammons & $304-198+30,43$ \\
\hline Name DezRA Ammons & Phone: $304-879-5921$ \\
\hline
\end{tabular}

\section{Can you give some time to Energy Express? Check the one (or more) that you might be able to do:

Usten to children read
Read to children
Work in the kitchen/cafeteria
Help in the office

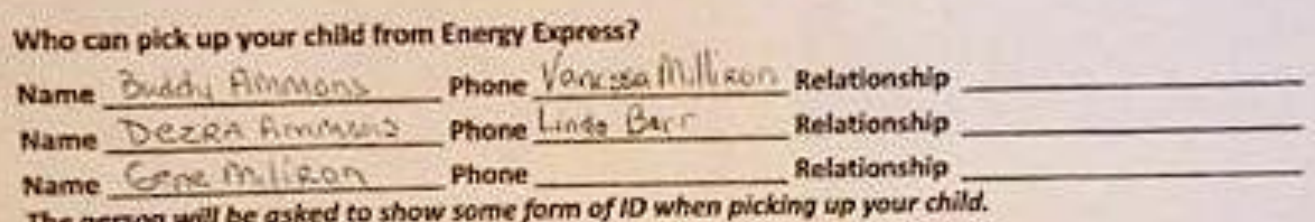
The person will be asked to show some form of 10 when picking up your child.

The Energy Express staff will ask your chlid questions or will use your chlid's written work to see if the program is working. What your child says or writes will not be recorded by his/her name but as part of an Energy Express growp. Your signature gives us permission to ask your child general questions or to use his/her work. This dges not affect your child's participation in Energy Express.

parent's or Guardian's signature

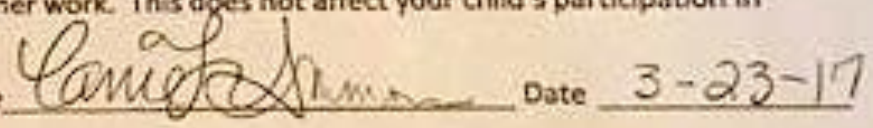

During Energy Express, photographs or tapes may be made of children in the program. These might be used in the newspaper, on our website, or in publicity about the program. Your signature gives us permisslon to use photographs or tapes of your child. Your answer does not affect your child's participation in Energy Express. Check which ones we may use:

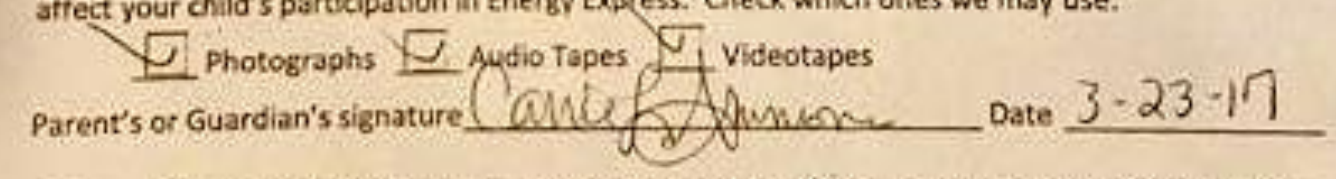

Energy Express welcomes parents and families and hopes that you will be able to join us for some activities. When could you attend something planned for parents and families?

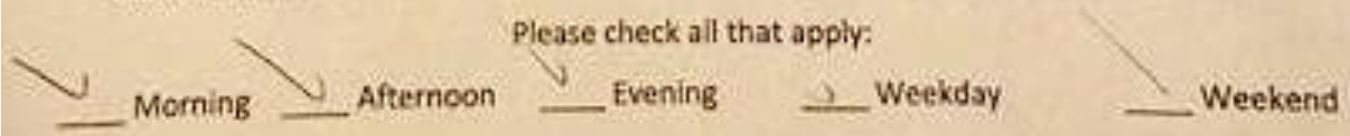




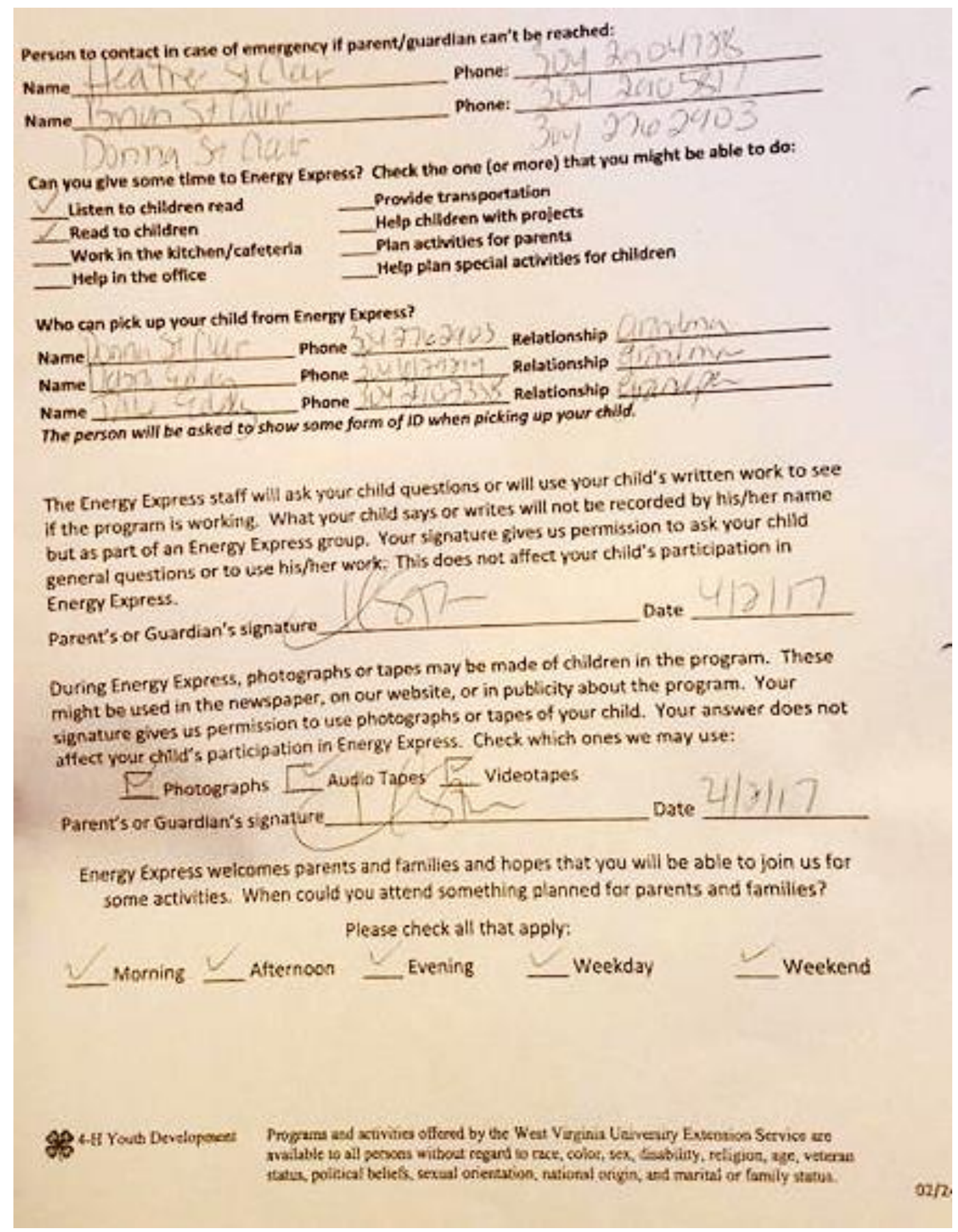


Person to contact in ease of emergency if patent/zuardian ear't be teached:

Name Debele Morere Phone: $304-432-8564$
Name Phone:

Can you give some time to Energy Express? Check the one (or more) that you might be able to do:

Listen to children read

fread to children

Work in the kitchen/cafeteria

Help in the office

\section{Provide transportation}

Help children with projects

Plan activities for parents

Heip plan special activities for children

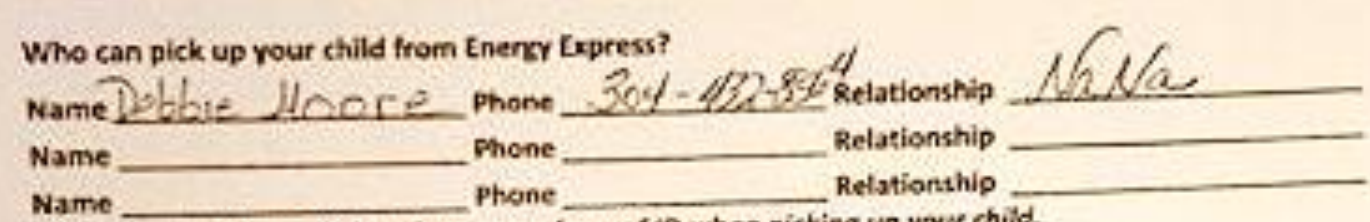

Name Phone Relistionship

The person will be osked to show some form of 0 when picking up your child

The Energy Express staff will ask your child questions or will use your child's written work to see if the program is working. What your ehifd says or writes will not be recorded by his/her name but as part of an Energy Express group. Your signature gives us permission to ask your child general questions of to use his/her work. This dees not affect your child's participation in Energy Express.

Parent's or Guardian's signature

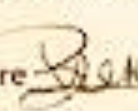

ar $+200,4$

Date $3-23-7$

During Energy Express, photographs or tapes may be made of children in the program. These might be used in the newspaper, on our website, or in publicity about the program. Your signature gives us permission to use photographs or tapes af pour child. Your answer does not affect your chald's participation in Energy Express. Check which ones we may use:

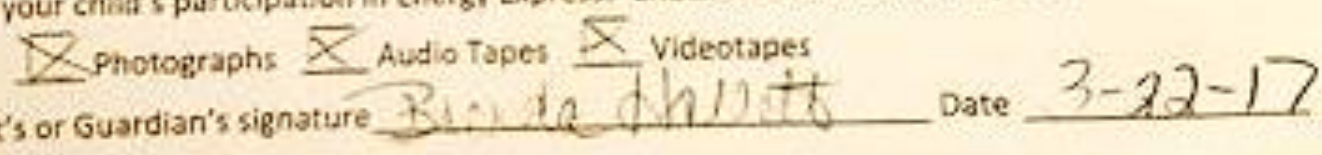

Enerby Express welcomes parents snd families and hopes that you wil be able to join us for some activities. When could you attend something planned for parents and families?

\section{Parent's or Guardian's signature \\ please check at that apply:}

Norning

Afternoon

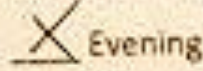

Weekday

Weekend 
Person fo contact in case of emergency if perent/cuardian can't be teached:

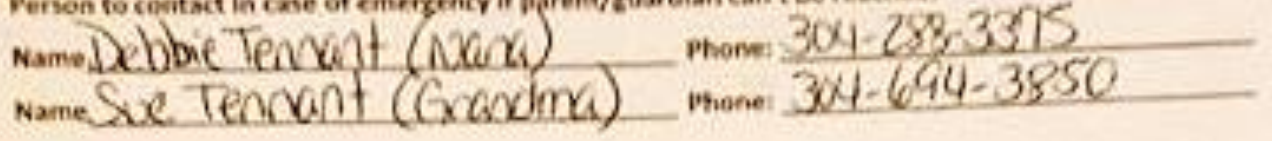

Can you give same time to Energy (spress) Check the one (or more) that vou might be able to do:

Uten to chididen read

Read to children

Work in the kitchen/catoteris

Heip in the oftice
Provide vansportation

Help children with projects

Plan activities for parents

Help plan sperial activities for children

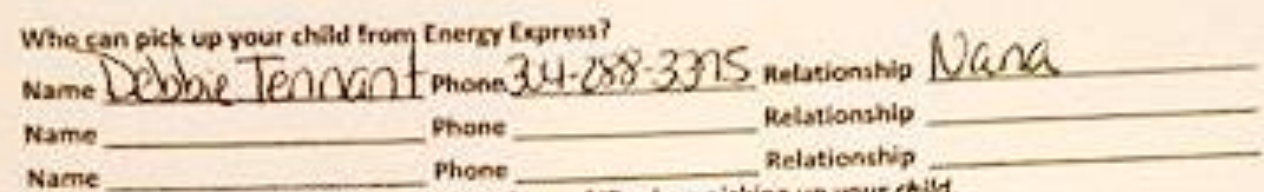

The person will be asked to shaw some form of 10 when picking up your child

The Energy Express staff will ask your child questions or will use vour child's written work to see If the grosram is working. What your child says or writes will not be recorded by his/her name but as part of an Energv Expcess group Your signature gives us permission to ask your child general questions or to use his/her work. This does not affect your child's participation in Enerav cearess:

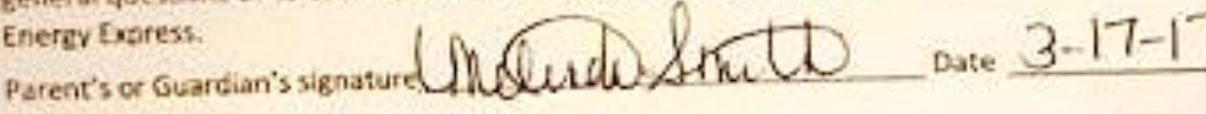

During Energy Express, photographs or tapes may be made of children in the program. Thess

In ght be used in the newspaper, on our website, or in publicity about the propram. Your sierature pives us permission to use photographs or tapes of your child. Your answer does not affect your chlid's participation in Eneser Express. Check whetch ones we may use

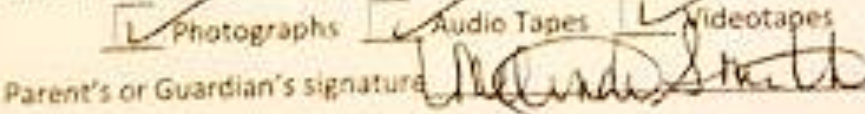

Energy Express welcomes parents and familes and hopes that you will be able to join us for some activities. When could you attend something planned for parents and families?
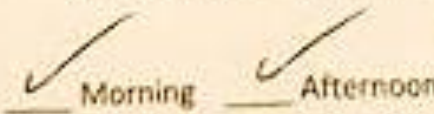

Please conck all that apply:

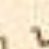
Evening

$\checkmark$ Weekday

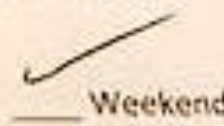

4. H Youth Deriopent

Prowara and activines offered by die Wea Virginia Univerity Eateratioa Service are

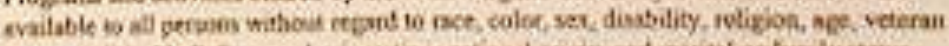

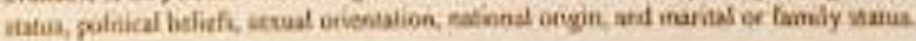




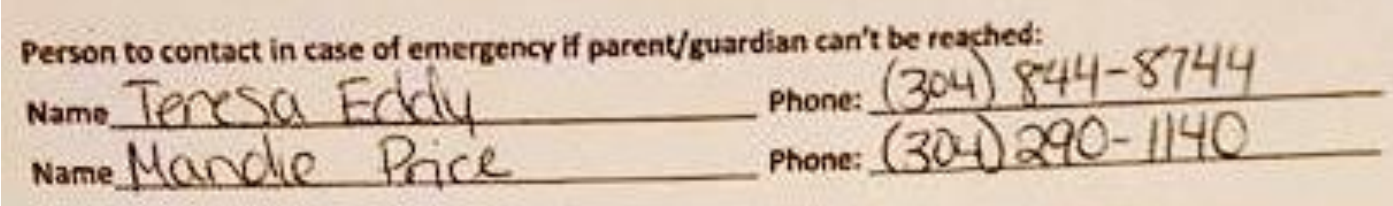

Can you give some time to Entrgy Express? Check the one (or more) that you might be able to do:

Listen to children read
Read to children
Work in the kitchen/cafeteria
Help in the office

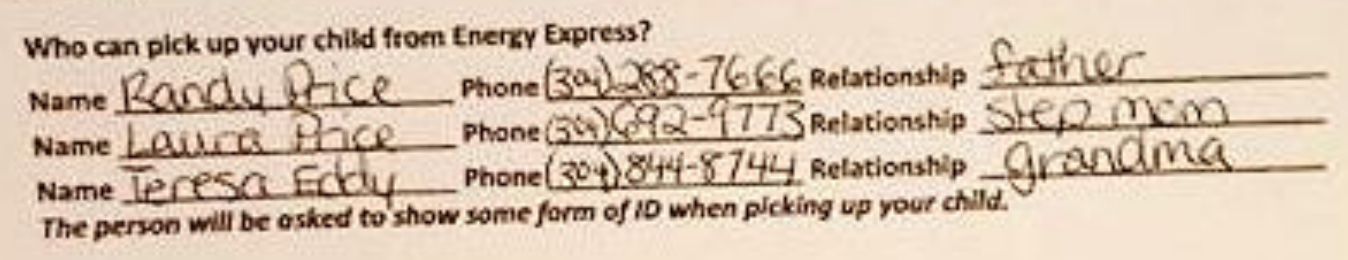

The Energy Express staff will ask your child questions or will use your child's written work to see if the program is working. What your chlld says or writes will not be recorded by his/her name but as part of an Energy Express group. Your signature gives us permission to ask vour child general questions or to use his/her work. This does not affect your child's participation in

Energy Express
Parent's or Guardian's signature Caula trece Date $3 / 23 / 17$ During Energy Express, photographs or tapes may be made of children in the program. These might be used in the newspaper, on our website, or in publicity about the program. Your signature gives us permission to use photographs or tapes of your child. Your answer does not affect your child's participation in Energy Express. Check which ones we may use:

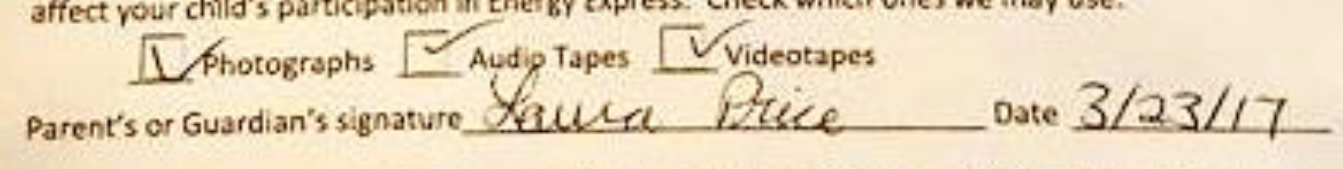

Energy Express weicomes parents and families and hopes that you will be able to join us for some activities. When could you attend something planned for parents and families?

Piease check all that apply:

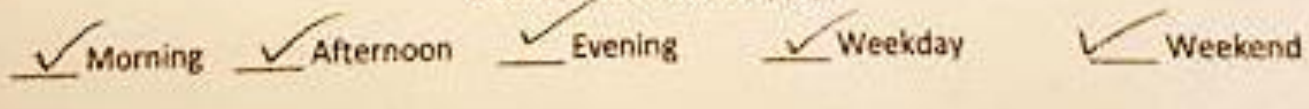




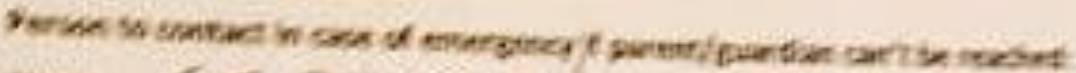

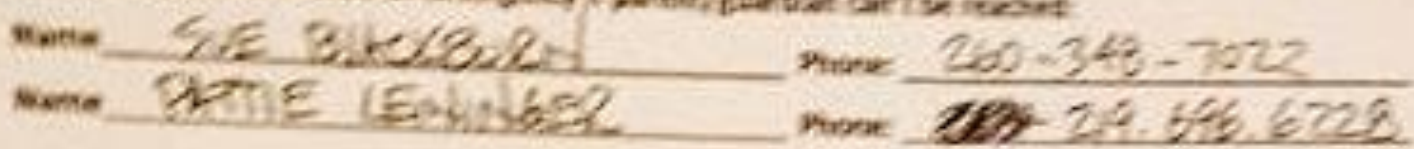

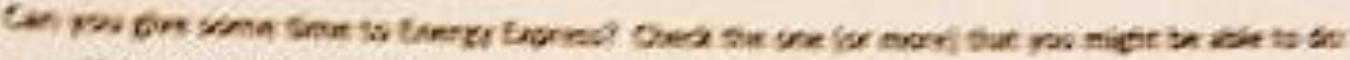
lacen ss owleres reat Head w salderen

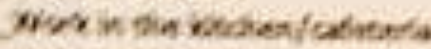
Melo in sin oflica

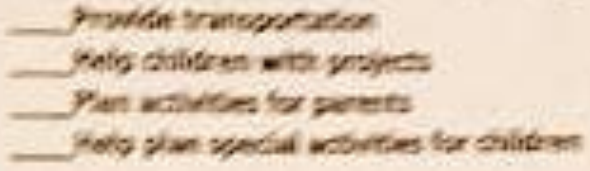

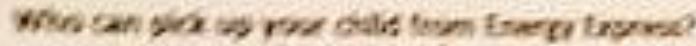

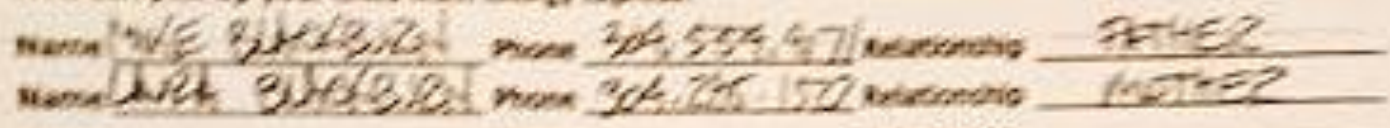

wern

hore

Ficarobis

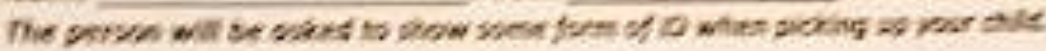

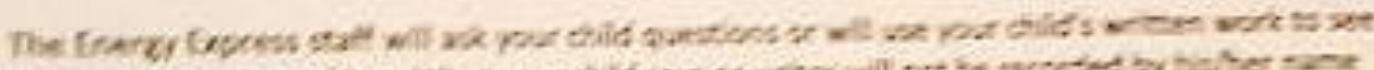

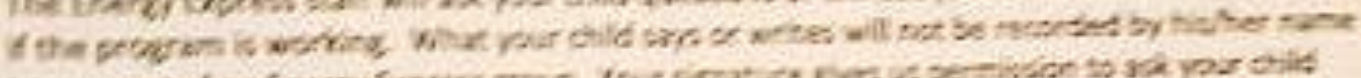

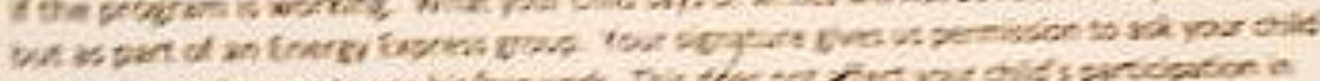

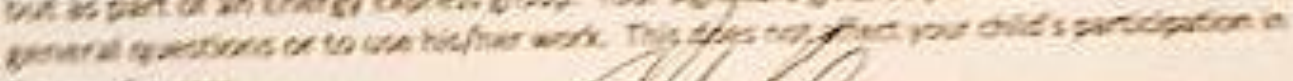
inergifasent.

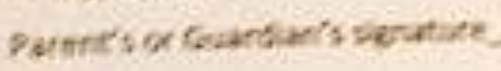

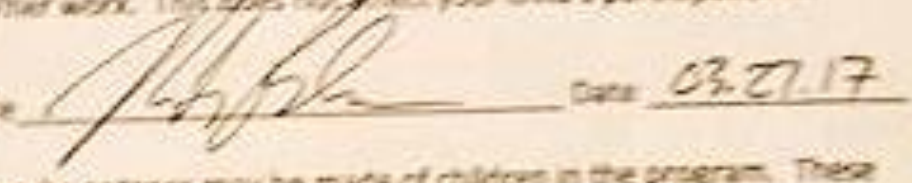

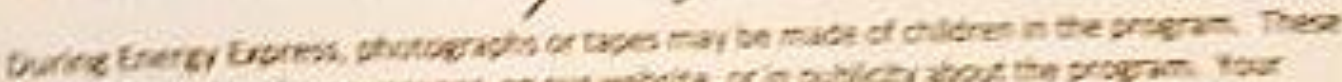

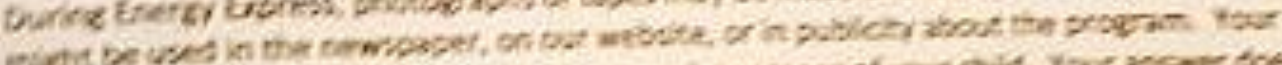

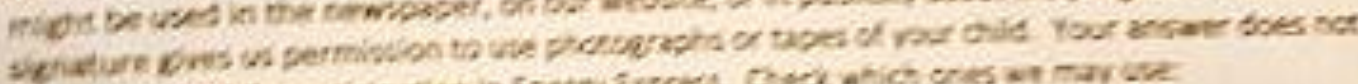

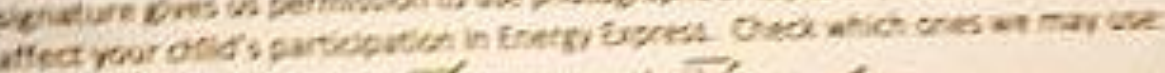

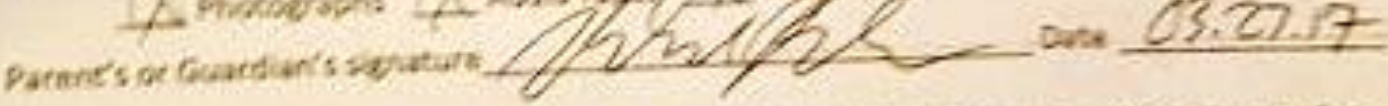

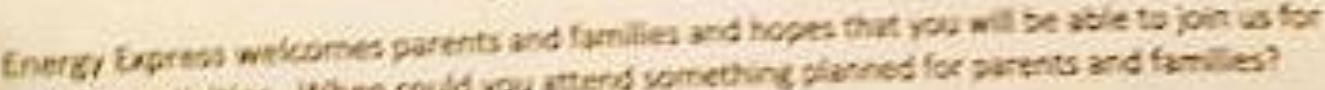

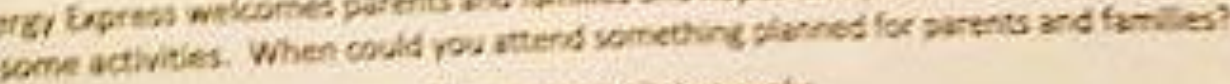
Mearing
Afuemoon $X$ Evening
Wents;
X. Weekend

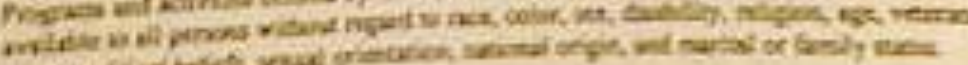

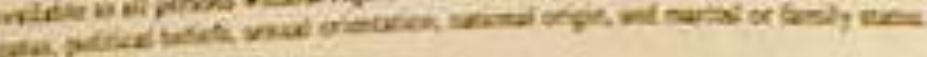




\section{LIST OF FIGURES}

i.

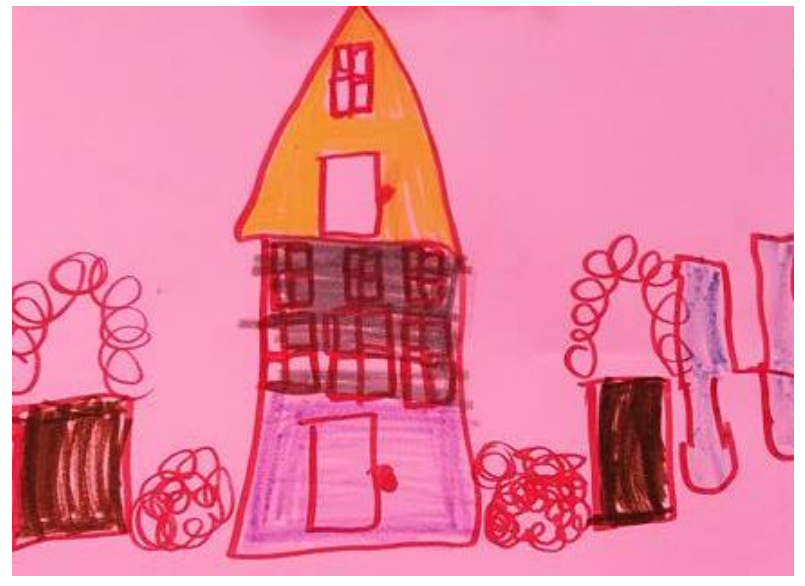

ii.

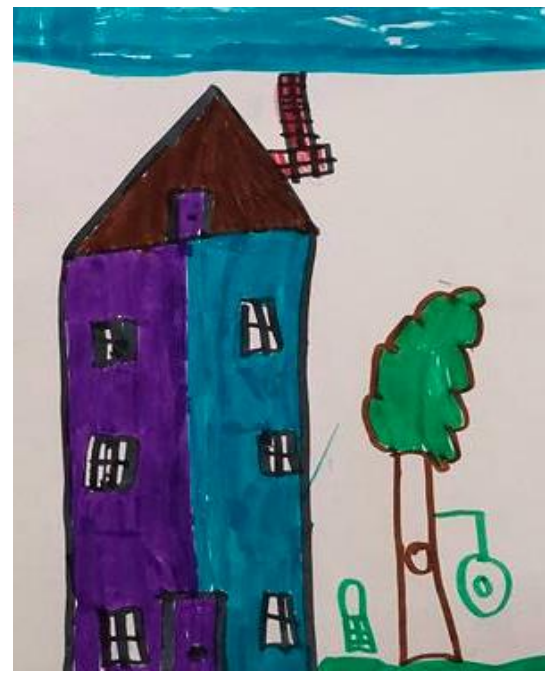

iii.

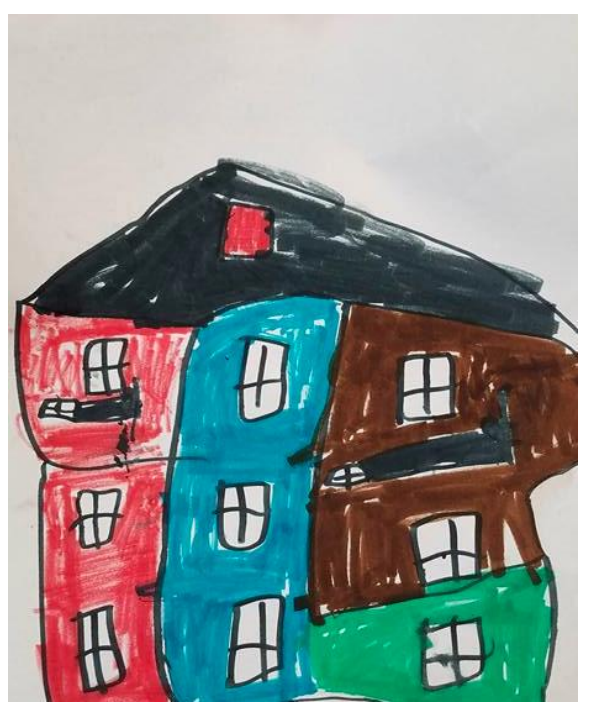



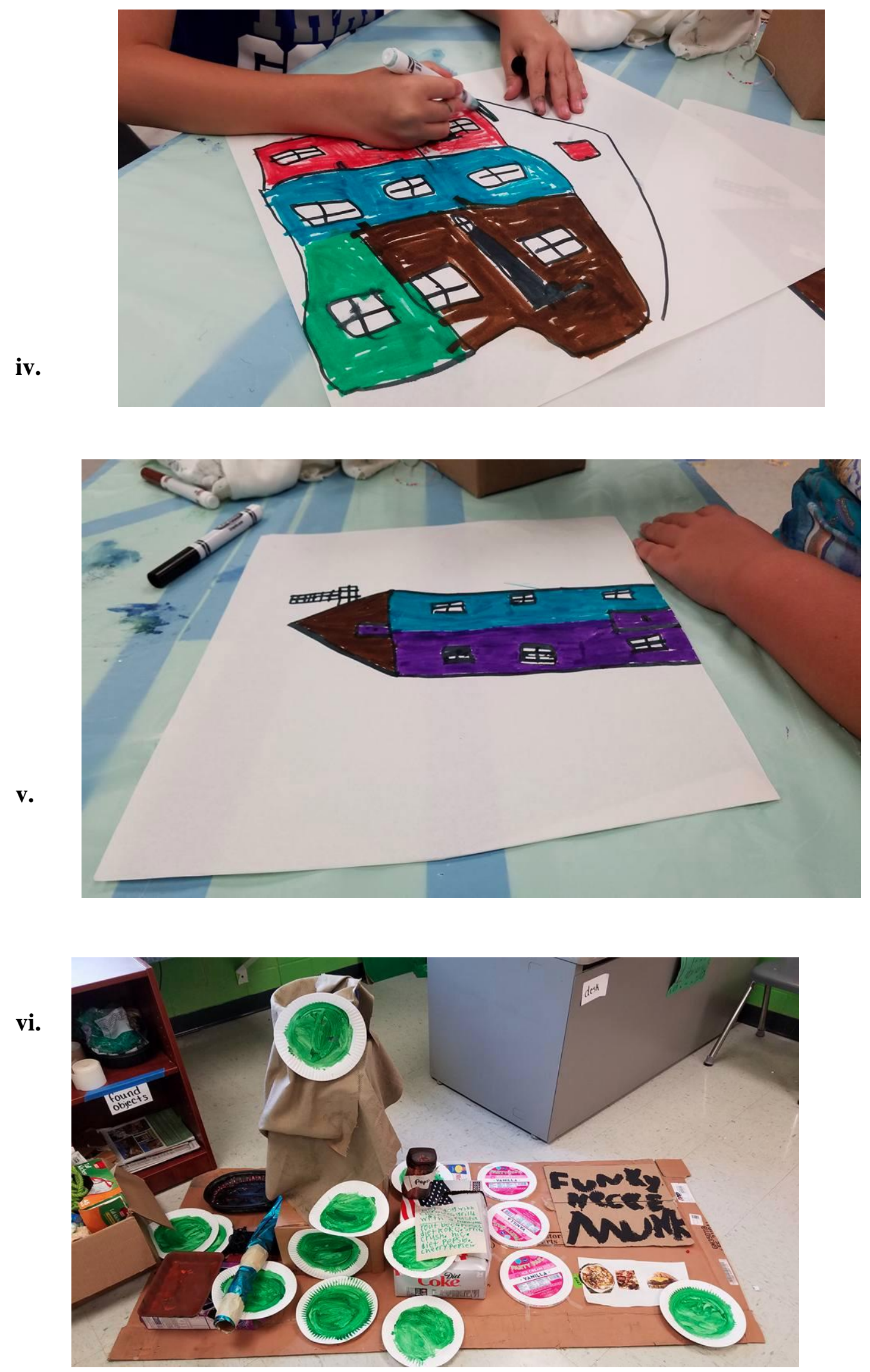
vii.

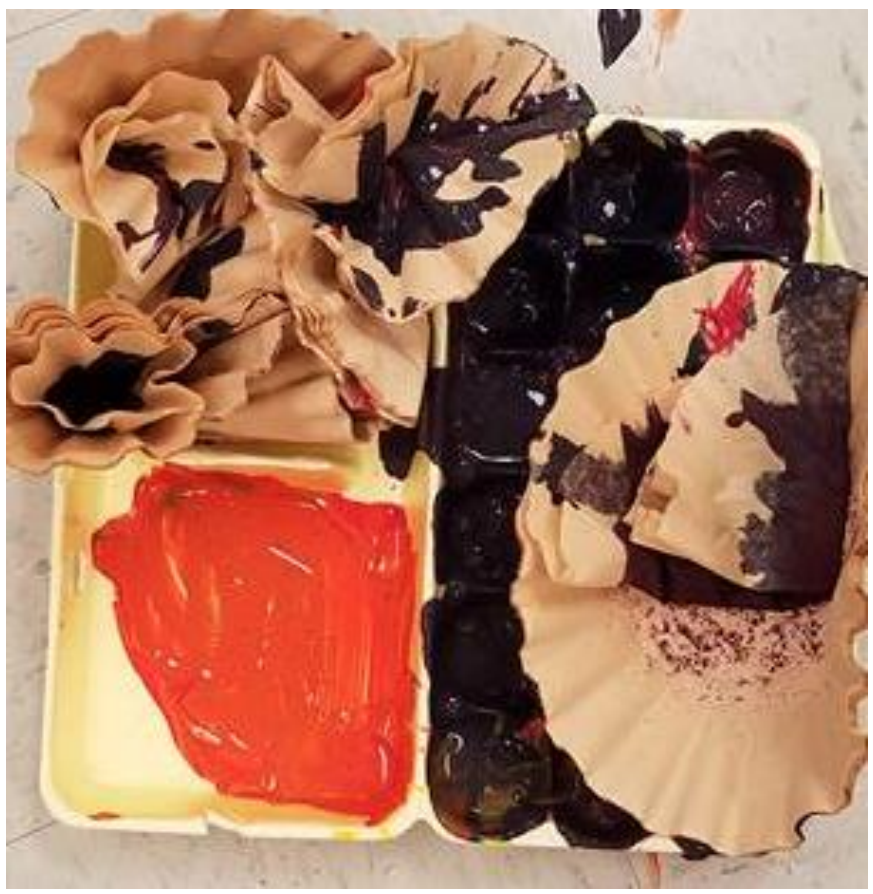

viii.

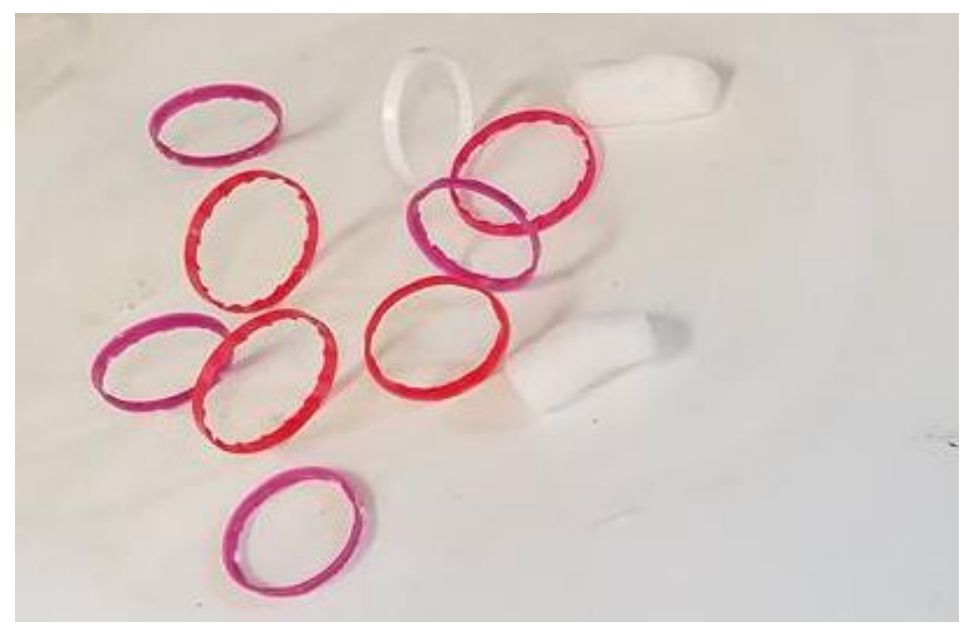



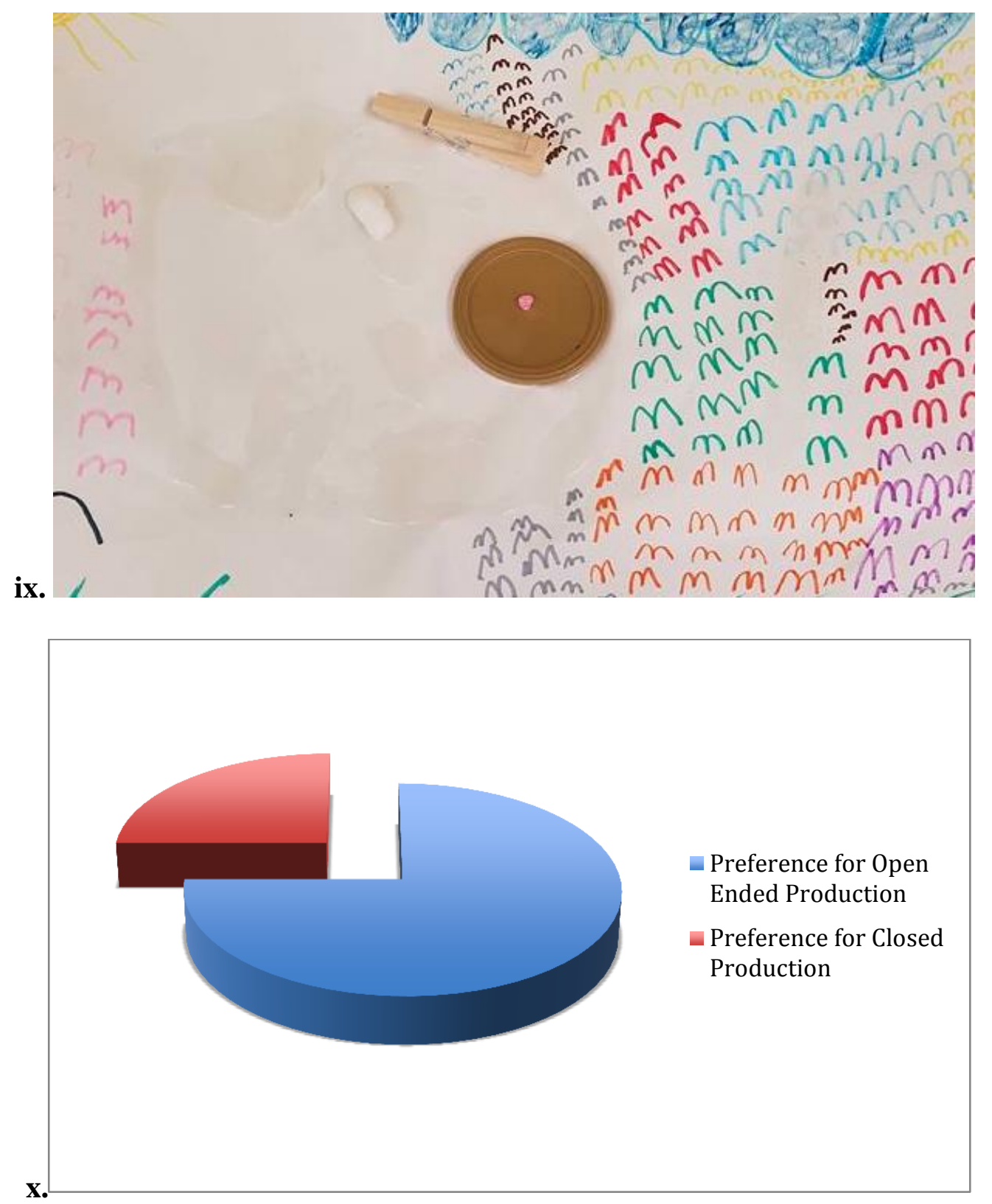